\title{
PROBABILISTIC SEISMIC PERFORMANCE AND LOSS ASSESSMENT OF A BRIDGE-FOUNDATION-SOIL SYSTEM
}

\author{
Brendon A Bradley*, Misko Cubrinovski, Rajesh P Dhakal, Gregory A MacRae. \\ Department of Civil Engineering, University of Canterbury, Private Bag 4800, Christchurch 8020, New Zealand \\ *Corresponding author: $\mathrm{Ph}+64-3-3667001$ ext 7673; Fax: +64-3-364 2758; \\ Email: brendon.bradley@canterbury.ac.nz
}

\begin{abstract}
This paper presents the probabilistic seismic performance and loss assessment of an actual bridge-foundation-soil system, the Fitzgerald Avenue twin bridges in Christchurch, New Zealand. A two-dimensional finite element model of the longitudinal direction of the system is modelled using advanced soil and structural constitutive models. Ground motions at multiple levels of intensity are selected based on the seismic hazard deaggregation at the site. Based on rigorous examination of several deterministic analyses, engineering demand parameters (EDP's) which capture the global and local demand and consequent damage to the bridge and foundation are determined. A probabilistic seismic loss assessment of the structure considering both direct repair and loss of functionality consequences was performed to holistically assess the seismic risk of the system.
\end{abstract}

It was found that the non-horizontal stratification of the soils, liquefaction, and soilstructure interaction had pronounced effects on the seismic demand distribution of the bridge components, of which the north abutment piles and central pier were critical in the systems seismic performance. The consequences due to loss of functionality of the bridge during repair were significantly larger than the direct repair costs, with over a $2 \%$ in 50 year probability of the total loss exceeding twice the book-value of the structure. 


\section{KEYWORDS}

Performance-based earthquake engineering (PBEE); soil-structure interaction (SSI); seismic loss estimation; downtime.

\section{INTRODUCTION}

Methods for assessment of the seismic performance of soil-structure systems have evolved significantly in the past two decades. This evolution has involved further improvement of simplified design-oriented approaches, and also development of more robust, and complex, analysis procedures. In addition to the development in methods of analysis, attention has shifted from the implicit assessment of seismic performance via seismic response analysis, to an explicit consideration of seismic performance based on the societal and economic consequences of seismic response and associated damage.

Consideration of the seismic response of soil-structure systems is complicated by the complexity of the ground motion excitation and the non-linear dynamic response of soilstructure systems. In addition to this complexity, the seismic response of soil-structure systems is burdened by a significant amount of uncertainty. Such uncertainty arises due to the uncertain nature of the future ground motions at the site, as well as the lack of knowledge of the properties governing the response of the soil-structure system. In addition to the ground motion and seismic response uncertainties, there are also uncertainties associated with the levels of damage to the structure and the corresponding consequences in terms of direct repair costs, loss of functionality, and human injuries.

Recent efforts [1-3], predominantly following the Pacific Earthquake Engineering Research (PEER) Centre framework formula [4], have focused on performance-based methodologies which allow the computation of seismic performance measures encompassing the direct and indirect consequences associated with the seismic response of engineered 
facilities, as well as addressing the significant aforementioned uncertainties in the seismic assessment problem.

Such performance and loss assessment methodologies have been primarily applied to assess the direct repair loss to structural systems such as office buildings [1-3, 5], with less attention to date devoted to the consideration of lifelines such as bridge structures, particularly those in which soil liquefaction can result in significant ground motion modification and demand to the structure and foundations. Furthermore, due to their increased complexity, indirect consequences due to loss of functionality have also not commonly received attention.

The focus of this paper is the probabilistic seismic performance and loss assessment of a two-span bridge structure supported on pile foundations which are founded in liquefiable soils. Firstly, the structure, site conditions, and computational model of the bridgefoundation-soil system are discussed. An overview of the seismic response of the system for a single ground motion is discussed to elucidate the predominant deformation mechanisms of the system and to identify the engineering demand parameters (EDP's) to use in the probabilistic seismic demand and loss assessments. Ground motions are selected in accordance with the seismic hazard deaggregation for various intensity levels, and the results of the seismic response analyses are used to perform probabilistic seismic demand and loss assessments of the system considering repair cost and loss of functionality consequences.

\section{CASE STUDY: FITZGERALD AVENUE BRIDGES}

\section{Details of the structure}

The Fitzgerald Avenue twin bridges (two bridges parallel to each other) are located to the north-west of central Christchurch, New Zealand. Each of the two-span bridges is $30 \mathrm{~m}$ long, $12.1 \mathrm{~m}$ wide and $3.2 \mathrm{~m}$ high (Figure 1a). The $15 \mathrm{~m}$ bridge deck spans consist of 21 prestressed concrete I-girders and cast-in-place concrete slabs. The bridge superstructure is 
supported on two seat abutments and one central pier (Figure 1b). The abutments and pier are $2.5 \mathrm{~m}$ high and are supported on pile foundations consisting of $8 \times 0.3 \mathrm{~m}$ diameter piles. All piles have continuous moment connections at the pile cap. At both abutments the bridge deck is seated on a $10 \mathrm{~mm}$ bearing pad as illustrated in Figure 1c.

The Fitzgerald Avenue bridges are a key link in Christchurch's transportation network carrying 38,000 vehicles daily. Because of their location in the transportation network, the Fitzgerald Avenue bridges have been designated by the Christchurch City Council as a key lifeline for post-earthquake services. A recent assessment of the existing bridge structure [6] recommended the installation of two additional bored piles at each of the abutments and central pier to a depth of $25 \mathrm{~m}$. These two additional piles on each side of the central pier are $1.5 \mathrm{~m}$ in diameter, while those at the abutments are $1.2 \mathrm{~m}$ in diameter.

\section{Site conditions}

Previous site investigations conducted to confirm ground conditions and assess material properties and liquefaction potential include: standard penetration tests (SPT's); cone penetration tests (CPT's) with direct push Dual Tubes (DT's); and the installation of piezometers. Based on these field investigations the generic soil profile for the longitudinal axis of the bridge given in Figure 2 was developed. The soil profile consists of four distinct layers. The shallowest two horizontal layers have thicknesses of $4.5 \mathrm{~m}$ and $6.5 \mathrm{~m}$, and normalised SPT blowcounts of $N_{l}=10$ and $N_{l}=15$, respectively. Below these two layers, the profile deviates from a simple horizontal layering, with a weaker layer of $6.5 \mathrm{~m}$ depth and SPT blowcount of $N_{l}=10$ on the left hand side of the model. Below $17.5 \mathrm{~m}$ on the left hand side of the model, and up to $11 \mathrm{~m}$ depth on the right hand side of the model is a significantly stiffer layer of $N_{l}=30$. Both the $N_{l}=10$ and $N_{l}=15$ layers are highly susceptible to liquefaction, while the $N_{l}=30$ base layer was deemed to be non-liquefiable. Behind the abutments, gravel backfills extend at an angle of 30 degrees to the ground surface. 


\section{COMPUTATIONAL MODEL}

A plane-strain finite element model of the longitudinal direction of the bridgefoundation-soil system was constructed for a seismic effective stress analysis [7]. While the seismic response of the bridge-pile-soil system is clearly a 3-dimensional problem, only plane strain analyses of the longitudinal direction are discussed herein. Details of the seismic effective stress analyses of the transverse direction of the bridge system are presented in Bowen and Cubrinovski [8] and Cubrinovski and Bradley [9].

Because of symmetry, the out-of-plane width of the longitudinal plane-strain model was taken to be half of the bridge width $(6.05 \mathrm{~m})$. That is, half of the bridge deck, abutments and piers were considered, as well as the same dimension for the soil thickness. Therefore, in the computational model, each abutment and the central pier are supported by a single $1.2 \mathrm{~m}$ and $1.5 \mathrm{~m}$ diameter pile, respectively. The $0.3 \mathrm{~m}$ diameter piles which supported the structure before the installation of the $1.2 \mathrm{~m}$ and $1.5 \mathrm{~m}$ piles provide negligible contribution and were not considered in the computational model.

The soil was modelled using an elastic-plastic constitutive model (S-D model) particularly tailored for modelling liquefaction problems $[10,11]$. The model combines two fundamental sand modelling concepts. The first is the state concept [12], where the sand stress-strain behaviour is characterised based on its combined density and confining stress state. The second is a modified elastic-plastic formulation with continuous yielding and hypoplasticity. The S-D model has been extensively verified through rigorous simulations of down-hole array records at liquefaction sites, seismic centrifuge tests, large-scale shake-table tests on pile foundations and case histories of damaged piles in the 1995 Kobe earthquake (e.g. [13] and references therein). Further details on the computation of the constitutive model parameters used in the analysis is given in Bowen and Cubrinovski [8] and Cubrinovski and Ishihara $[10,11]$. 
The bridge abutments, central pier and pile foundations were modelled using non-linear beam elements (multiple elements with an approximate length of $1 \mathrm{~m}$ ). The moment-curvature response was parameterized by a hyperbolic curve, with the initial stiffness, $E I$, and peak moment, $M_{F}$, chosen to match the moment curvature relationship of the pile [8]. The unloading/reloading path for the moment-curvature relationship is based on the Masing rule [14], and no strength degradation was considered due to limitations of the constitutive model for the beam elements. The bridge superstructure was modelled as linear elastic because of its significantly higher axial stiffness compared to the lateral stiffness of the abutments/piers and its higher flexural and shear strength. Possible displacement of the deck relative to the abutment (due to slip on the bearing pads) was modelled with a rigid-plastic spring with a sliding force computed from the concrete-rubber interface friction $(\mu=0.3)$ and the tributary weight of the deck.

A static analysis was first performed in order to determine the initial stress distribution in the soil. In particular, a correct distribution of shear stresses near the abutments is critical for modelling the driving stresses for lateral spreading of soil toward the river channel. In addition to hysteretic damping occurring as a result of the inelastic constitutive models, Rayleigh damping was used to provide enhanced numerical stability with parameters $\alpha=0$ and $\beta=0.005$.

\section{SEISMIC HAZARD AND GROUND MOTIONS}

The seismic hazard due to earthquake-induced ground motion is determined using probabilistic seismic hazard analysis (PSHA) [15]. In order to obtain the seismic hazard curve it is first necessary to specify which ground motion intensity measure (IM) is to be used. In this study, $P G A$ is used as the IM, both for its historical use and because $P G A$ and spectral accelerations at various periods, are the only IM's for which seismic hazard curves are publicly available for this site. Recent studies [16] have shown however that velocity-based 
IM's (e.g. peak ground velocity, $P G V$, and spectrum intensity, $S I$ ) are better (based on reduced bias and uncertainty) IM's for such analyses of structures in liquefiable soils. As advanced ground motion prediction equations for these IM's are available (e.g. Bradley et al. [17] and Boore and Atkinson [18]), the development of seismic hazard curves for such IM's should be a future focus in performance-based geotechnical earthquake engineering. As will be seen in the following sections, the choice of $P G A$ as the IM leads to significant scatter in the results of the seismic response analyses.

Figure $3 \mathrm{a}$ illustrates the ground motion hazard at the site of the bridge structure, while Figure $3 \mathrm{~b}$ and Figure $3 \mathrm{c}$ illustrate the deaggregation and target spectra necessary for ground motion selection [19]. Ground motion selection in accordance with the seismic hazard deaggregation has been shown to be important [20], particularly for inefficient and insufficient IMs such as $P G A$. As noted in Stirling [21], and evident in Figure 3b, the seismic hazard is dominated by: (i) $M_{W}=5.5-6.5$ earthquakes at short distances $(R=15-30 \mathrm{~km})$, associated with background seismicity, and (ii) larger $M_{W}=6.9-7.6$ earthquakes on mapped faults ranging from $R=25-50 \mathrm{~km}$.

Ground motions were selected for seismic response analyses at 9 different intensity levels as shown in Figure 3a and Table 2. For each intensity level, ground motions were selected from the NGA database [22] based on the $M_{w}, R$ and $\varepsilon$ deaggregation from PSHA (e.g. Figure 3b). A further constraint of an amplitude scale factor in the range, $S F=0.6-1.6$, was used to reduce response bias [23] and help ensure that ground motions with the correct frequency content (i.e. spectral shape) were selected. Because of the larger recurrence intervals and resulting ground motions of earthquakes on mapped faults, deaggregation at large exceedance probabilities was dominated by the background seismicity, while the hazard at small exceedance probabilities was dominated by the mapped faults. This source variation was considered in ground motion selection by, for example: $90 \%$ of the selected ground 
motions being based on scenario type (i) (i.e. $\mathrm{M}_{\mathrm{w}}=5.5-6.5, \mathrm{R}=15-30 \mathrm{~km}$ ) and $10 \%$ on scenario type (ii) for the lowest, IM level one; $80 \%$ vs. $20 \%$ at IM level two and so on (i.e. at IM level 9 there were $10 \%$ of ground motions due to scenario type (i), and $90 \%$ of type (ii)).

Based on the above criteria, the ground motions shown in Table 3 were selected and used in the seismic response analyses to follow. For each IM level, ten ground motion records, each containing two orthogonal ground motion components, were selected, giving a total of 180 ground motions for seismic response analyses. Ground motions were linearly (i.e. amplitude) scaled based on the rotation independent geometric mean of the two orthogonal components [24]. Because of the range of scale factors allowed $(0.6<\mathrm{SF}<1.6)$ some ground motions were acceptable for two or more IM levels as illustrated in the right-hand column of Table 3.

\section{DETERMINISTIC PERFORMANCE ASSESSMENT}

Before conducting the probabilistic seismic response analyses with multiple ground motions and at multiple intensity levels, it was considered important to first rigorously examine the characteristics of the response of the system using detailed seismic effective stress analysis. This is important for understanding the development of excess pore water pressures, ground response features, soil-structure interaction, and the predominant deformation mechanisms which control the seismic response of the system. The latter point, in particular, is necessary before conducting probabilistic effective stress analyses since the number of analyses employed in the probabilistic assessment means it is not feasible to examine each analysis in detail, but rather a set of engineering demand parameters (EDP's) are used to indicate the seismic response. Thus an understanding of the deformational mechanism and response of the system is critical in the selection of appropriate EDP's. To that goal, the response of the system to an appropriate ground motion at various levels of intensity was rigorously examined using deterministic effective stress analysis. Due to space 
limitation only the response of the computational model for a single ground motion scaled to an intensity level with a $2 \%$ probability of exceedance in 50 years is presented herein.

\section{Foundation soil response}

Figure 4 illustrates the scaled acceleration time history and acceleration response spectra for the Loma Prieta Gilroy Array \#3 $\phi=90$ ground motion (ID = 767 in Table 3), which was used as the input ground motion in the deterministic seismic response analysis. The geometric mean of this motion (not the individual component) was scaled to the $2 \%$ in 50 year exceedance value of $0.463 \mathrm{~g} P G A(S F=1.002)$.

Figure 5 illustrates the development of excess pore pressures and eventual liquefaction in the soil surrounding the bridge computed in the effective stress analysis. It can be seen that pore pressure ratios in the range, $E P W P R=0.2-0.5$, first develop in the bottom $N_{l}=10$ layer on the left hand side of the model and at the base of the $N_{l}=15$ layer on the right hand side of the model. The bottom $N_{l}=10$ layer has almost entirely liquefied by 6.0 seconds. As shaking progresses with time, pore water pressures continue to increase in the right hand side of the $N_{l}=15$ layer, and the re-distribution of excess pore pressures causes spreading of liquefaction to shallower depths (predominantly on the left hand side of the model).

Figure 6a illustrates excess pore water pressure ratios $45 \mathrm{~m}$ to the left of the bridge. The three depths of $z=6.15,14.75$, and $19.75 \mathrm{~m}$ are located in the $N_{l}=15,10$, and 30 layers, respectively. In agreement with Figure 5, it can be seen that complete liquefaction of the $N_{l}=10$ (i.e. $z=-14.75 \mathrm{~m}$ ) layer develops by $\mathrm{t}=7.0 \mathrm{~s}$. Liquefaction of the bottom $N_{l}=10$ layer also reduces the ground motion intensity in the above soil layers, preventing liquefaction from eventuating at $\mathrm{z}=6.15 \mathrm{~m}$. Figure $6 \mathrm{~b}$ illustrates the shear stress-strain response of the soil at $z=-14.75 \mathrm{~m}$, with peak shear strains of up to $2.5 \%$.

\section{Bridge and pile response}

Figure 7a illustrates the displacement time histories at the three footings of the bridge, 
and the north and south free-field response (all at a depth of $z=-3.2 \mathrm{~m}$ ). In the first $7.0 \mathrm{~s}$, it is apparent that the displacement in the north free-field is larger than the south free-field and footing displacements, which are essentially identical. After $\mathrm{t}=7.0 \mathrm{~s}$, relative displacements between the three footings are apparent due to significant liquefaction occurring in the surrounding soils. It is also apparent in Figure $7 \mathrm{a}$ that the displacement histories of the footings are not completely in-phase with the free-field response (both north and south). Figure $7 \mathrm{~b}$ provides a comparison of the acceleration histories at the north free-field $(z=0 \mathrm{~m})$, central pile cap, and at $27.5 \mathrm{~m}$ depth, near the base of the model. It can be seen that the stiffening effect of the pile foundations allows waves of significantly higher amplitude and frequency to propagate to the central pier cap than to the free-field surface where significant soil liquefaction occurs. This stiffening effect is the reason for the aforementioned out-ofphasing and smaller amplitude of the footing displacements in Figure 7a compared to that in the north free-field.

Figure 8a illustrates the bending moment profiles in the piles and abutments/pier at $t=5.15 \mathrm{~s}$ which corresponds to the peak footing displacements in Figure 7a. It can be seen that the seismic demand on the pile foundations is significant with both north and central piles exceeding their respective yield moments, and the south piles exceeding the cracking moment. The variation in the $N_{l}=10$ to $N_{l}=30$ boundary depth (e.g. Figure 2 ) is also observed to have a pronounced effect on the depth at which the peak negative bending moment is developed in the piles. The effect of this depth variation also causes larger soil displacements on the north side of the model relative to the south. As the large axial stiffness of the bridge superstructure effectively enforces equal displacements of the top of the abutments (with the exception of seating displacement discussed in the next paragraph), this variation in soil displacements in the horizontal direction also causes significantly different moments in the upper half of the piles and the abutments/pier. Figure $8 \mathrm{~b}$ illustrates the shear force histories for the two 
abutments and central pier. It is immediately evident that forces in the north and south abutments are of opposite sign indicating that the bridge superstructure is predominately restraining the displacements of the north abutment/piles (where soil displacements are relatively large), and increasing the displacement of the south abutment/piles (where soil displacements are relatively smaller).

Figure 9 illustrates the relative displacement between the bridge superstructure and abutment (herein referred to as seating displacement) at the north and south abutments (the superstructure is fixed to the central pier). The maximum seating displacement of $10 \mathrm{~cm}$ at the south abutment is significantly large to require some post-earthquake inspection and repair (i.e. Table 4). In addition, explicitly accounting for the seating displacement restricts the maximum shear force which can be transmitted between the bridge superstructure and the north and south abutments, which was observed to reduce the bending moments in the abutments relative to those in the central pier.

\section{PROBABILISTIC SEISMIC RESPONSE ANALYSES}

Clearly a vast amount of information and insight into the seismic response of the entire bridge-foundation-soil system is possible by rigorously examining such seismic effective stress analyses discussed in the previous section. However, the results of a single seismic effective stress analysis do not allow for explicit consideration of the rate of exceedance and uncertainties in the characteristics of the incident ground motion or the consequences associated with the seismic response. Consideration of the uncertainties associated with the incident ground motion can be accounted for by subjecting the developed numerical model of the system to multiple ground motions of various levels of intensity. This section discusses the results of these probabilistic seismic response analyses using the aforementioned ground motions selected from seismic hazard deaggregation.

Based on the observations of various deterministic analyses, a total of nine different 
engineering demand parameters (EDP's) were monitored in each of the analyses discussed in this section. These EDP's were: peak curvature throughout the length of each of the three piles; peak curvature in the abutments and central pier; maximum seating displacement at the two abutments; and the maximum value of the vertical settlement of the bridge approach embankments. As discussed in the previous sections, peak ground acceleration (PGA) was used as the ground motion intensity measure.

\section{Piles and abutments/pier}

Figure 10 illustrates the results of the seismic response analyses for twenty ground motions at nine intensity levels for peak curvature in the north, central, and south piles; north and south abutments; and central pier. Several points are worthy of note in Figure 10. Firstly, as expected, the mean seismic demand for each of the EDP's increases with an increase in the input ground motion intensity. Secondly, there is a large amount of variation in the magnitude of the results for a given value of $P G A$ (e.g. for $P G A=0.46 \mathrm{~g}$ the peak curvature in the north pile ranges from 0.0004 to 0.005 ). This large variation occurs because of the aforementioned inefficiency of $P G A$ as a ground motion intensity measure for the seismic response of soft soil deposits (but the fact that seismic hazard for superior intensity measures do not exist for this site). Thirdly, there is a significant variation in the level of seismic demands for the different pile and abutment/pier components depending on their location in the bridge-foundation-soil system.

As observed in the deterministic analysis discussed in the previous section, the curvature demand for the north piles is larger than the other two piles because of the larger soil displacements at this location due to the variation in the depth of the $N_{l}=10$ to $N_{l}=30$ soil layer boundary. The central pier is also observed to have a higher curvature demand than that in the north and south abutments. This higher demand in the central pier occurs primarily due to the fixed connection between it and the superstructure, while sliding of the abutment- 
superstructure connections limits the maximum shear forces, and hence moment, in the abutments.

\section{Deck seating displacement}

Figure 11 illustrates the results of the probabilistic seismic response analyses for the maximum seating displacements at the north and south abutments. As noted in regard to Figure 10 it is again observed that there is significant scatter in the peak seating displacements for a given $P G A$. It can be seen that even for small levels of ground motion (PGA $>0.2 \mathrm{~g}$ ) there is a significant likelihood of the maximum seating displacement exceeding the median value for minor repair (i.e. Table 4). The likelihood of complete unseating failure is however significantly low over all levels of PGA considered.

\section{Approach settlements}

Significant liquefaction of foundation soils and lateral spreading can cause large settlements of the ground near the approaches to a bridge superstructure. Figure 12 illustrates the maximum vertical settlements computed at the approaches to either side of the bridge superstructure. It can be seen that significant settlements of up to $0.4 \mathrm{~m}$ were computed, and also that the dispersion in the magnitude of the settlement is significant. Ground motions above $0.2 \mathrm{~g}$ PGA have a high likelihood of causing vertical settlements which will require minor post earthquake repair, while significant approach settlements requiring major earthworks are likely only under large ground motions (i.e. $P G A>0.6 \mathrm{~g}$ ), with the exception of some 'outlying' responses at $0.355 \mathrm{~g}$ PGA.

\section{SEISMIC DEMAND HAZARD}

By combining the seismic response analyses obtained in the previous section (with EDP|IM having a lognormal distribution), which account for the variability in response due to complex ground motion excitation, with the seismic hazard curve, describing the likelihood of 
various levels of ground motion, it is possible to compute the annual rate of exceeding various levels of demand for each of the different EDP's monitored. Mathematical and computational details of computing the annual rate of exceeding various levels of demand can be found in, for example, Bradley et al. [2].

Figure 13a illustrates the annual rate of exceeding various levels of peak pile curvature for each of the three piles in the computational model. The effect of the variation in demand for the piles observed in Figure 10 is also apparent in Figure 13a. Based on the monotonic moment-curvature relationship of the piles the median values of the cracking, yielding, and ultimate damage states (Table 4) are also given in Figure 13a. It can be seen that the north and south piles are more vulnerable (i.e. have higher damage state exceedance rates) than the larger $1.5 \mathrm{~m}$ diameter central pile, with the north pile particularly vulnerable for higher levels of curvature. Figure $13 \mathrm{~b}$ illustrates the annual rate of exceeding various levels of peak curvature of the abutments and central pier. As observed in Figure 10, it can be seen that the demand on the central pier is significantly greater than that for the north and south abutments, with the central pier having annual damage state exceedance frequencies typically an order of magnitude larger than the abutments.

Figure 14a illustrates the annual rate of exceeding various levels of peak seating displacement at the north and south abutments. It can be seen that the annual rate of exceedance for various levels of demand at both the north and south abutments is quite similar. The exceedance rates for the displacement corresponding to the median value for minor repair (Table 4) are slightly above $1 \times 10^{-3}$, while those for deck unseating are approximately $1 \times 10^{-5}$. Figure $14 \mathrm{~b}$ illustrates the annual rate of exceeding specified levels of approach embankment vertical settlement. It can be seen that the exceedance rates for the median values corresponding to minor and major repair are quite large (approximately $1 \times 10^{-3}$ and $1 \times 10^{-4}$, respectively). 


\section{PROBABILISTIC SEISMIC LOSS ASSESSMENT}

The seismic risk of the bridge-foundation-soil system in terms of the explicit loss consequences due to structural response may be viewed as ultimate measures of seismic performance for decision making. In order to conduct such a seismic loss assessment, the consequences, in the form of direct repair cost and repair duration, due to various states of damage for each of the components of the system are required. To this end, a professional cost estimator was engaged to develop cost estimates and repair durations due to various levels of damage in each of the components of the Fitzgerald Bridge, a summary of which is given in Table 4. Particular points of note in Table 4 are: (i) no repair actions are performed for cracking in the pile foundations; (ii) the ultimate curvature capacity of the piles is less than that given by a monotonic moment-curvature analysis (i.e. Table 1) because of cyclic degradation effects; (iii) because the repair of cracking in the central pier can be done without removing the abutment backfills it causes less delay than repairing the abutments.

A recent network traffic flow analysis [26] which estimated the travel delay and vehicle running costs due to inoperability of the Fitzgerald Avenue twin bridges at $\$ 10,720$ /day was used to convert repair durations to loss of functionality costs.

\section{Loss assessment framework}

The loss assessment presented herein employed the seismic loss assessment tool, SLAT and is based on the PEER framing formula [4]. The treatment of the direct repair losses is the same as that of Bradley et al. [2] and Aslani [1], and is only briefly mentioned here. The treatment of repair duration losses presented here is novel and is discussed in greater detail below.

Each of the components of the bridge-foundation-soil system (i.e. piles, abutments) are denoted as performance groups (PG's), and for a given ground motion intensity the expectation and variance in the loss to each performance group is defined as [e.g. 1, 2]: 


$$
\begin{gathered}
\mu_{L_{i} \mid M}(i m)=\int \mu_{L_{i} \mid E D P}(e d p) f_{E D P \mid M}(e d p \mid i m) d E D P \\
\sigma_{L_{i} \mid M M}^{2}(i m)=\int\left[\mu_{L_{i} \mid E D P}^{2}(e d p)+\sigma_{L_{i} \mid E D P}^{2}(e d p)\right] f_{E D P \mid M}(e d p \mid i m) d E D P-\mu_{L_{i} \mid M}^{2}(i m)
\end{gathered}
$$

where $\mu_{L_{i} \mid M}(\mathrm{im})$ and $\sigma_{L_{i} \mid I M}^{2}(\mathrm{im})$ are the expected value and variance in the loss (either direct repair cost or repair duration) of PG $i$ given $I M=i m ; \quad \mu_{L_{i} \mid E D P}(e d p)$ and $\sigma_{L_{i} \mid E D P}^{2}(e d p)$ are the mean and variance in the loss of PG $i$ given $E D P=e d p$, respectively; and $f_{E D P \mid M}(e d p \mid i m)$ is the probability density function (pdf) for the EDP|IM relationship. The mean and variance in the loss of PG $i$ given $E D P=e d p$ are obtained by combining the damage fragility and loss data given in Table 4 using the total probability theorem [e.g. 1, 2], while $f_{E D P \mid M}(e d p \mid i m)$ is obtained from the results of the probabilistic seismic response analyses (e.g. Figure 10-Figure 12).

The total direct repair loss of the bridge-foundation-soil system is assumed $[1,3,5]$ to be the simple summation of the losses due to each PG. Thus the mean and variance in the total direct repair cost can be given by [e.g. 1, 2]:

$$
\begin{gathered}
\mu_{L_{R} \mid M, N C}(i m)=\sum_{i=1}^{N_{P G}} \mu_{L_{i} \mid I M}(i m) \\
\sigma_{L_{R} \mid M, N C}^{2}(i m)=\sum_{i=1}^{N_{P G}} \sigma_{L_{i} \mid M}^{2}(i m)+2 \sum_{i=1}^{N_{P G}} \sum_{j=1}^{i-1} \rho_{L_{i}, L_{j} \mid I M}(i m) \sigma_{L_{i} \mid I M}(i m) \sigma_{L_{j} \mid I M}(i m)
\end{gathered}
$$

where $N_{P G}$ is the number of performance groups and $\rho_{L_{i}, L_{j} \mid l M}(\mathrm{im})$ is the correlation between the loss given $I M=i m$ for PG's $i$ and $j$ [27].

Unlike direct repair costs, it is unreasonable to simply assume that the total repair time to fix the entire bridge-foundation-soil system will be the sum of the repair durations for each component, since components can be fixed in parallel. To facilitate the computation of the repair duration ('downtime'), the idea of repair groups (RG's) is introduced here. A repair 
group has two distinct parts: (i) various PG's comprising the RG which must be repaired in a serial manner, and (ii) various other precursor RG's which must be first completed, before work on the particular repair group under consideration may commence. Mathematically speaking the time to complete repairs in repair group $i$ given IM, $L_{R G_{i}} \mid I M$, is given by:

$$
L_{R G_{i}}\left|I M=\sum_{j=1}^{N_{P G, R G_{i}}} L_{j}\right| I M+\max _{j=1: N_{R G, p r e}}\left[L_{R G_{j}} \mid I M\right]
$$

where $N_{P G, R G_{i}}$ is the number of PG's in $R G_{i}$; and $N_{R G_{i}, p r e}$ is the number of precursory RG's for RG $i$. Defining RG's as been comprised of various PG's as well as various precursor RG's has intentionally been made similar to typical Gantt chart construction scheduling software.

For the Fitzgerald Avenue twin bridges a total of five repair groups were considered as indicated in Table 5. $R G_{1}$ to $R G_{3}$ correspond to repair of components at the North, central, and South regions of the bridge; $R G_{4}$ to the approach embankments; and $R G_{5}$ to total repair of the bridge structure. The relatively simple configuration of the Fitzgerald Avenue twin bridges means the composition of the repair groups is not overly complicated, although the formulation of Equation (5) can easily handle more complex cases. It should be noted that because of the nature of Equation (5), it is not possible in general to estimate the statistical moments (i.e. mean and variance) of the repair duration for each of the repair groups in closed form, as was the case for direct repair cost (i.e. Equations (3) and (4)). Thus, after obtaining the statistical moments for all of the PG's using Equations (1) and (2), Monte Carlo simulation (with appropriate consideration of the correlation in the loss between multiple PG's [27]) was used to estimate the distribution of $L_{R G_{i}} \mid I M$. In particular, it should be noted that the expectation of the maximum of multiple random variables is not equal to the maximum of their expectations (i.e. $E\left[\max \left(X_{1}, . ., X_{n}\right)\right] \neq \max \left(E\left[X_{1}\right], . ., E\left[X_{n}\right]\right)$ ), as used in Mitrani-Reiser [28]. 


\section{$L \mid I M$ results}

Figure 15 illustrates the distribution of the direct repair loss and downtime for the bridge-foundation-soil system as a function of peak ground acceleration, $P G A$. It is observed that above $0.1 \mathrm{~g} P G A$, both measures of loss rise steeply with increasing $P G A$, and that there is significant uncertainty in the losses as illustrated by the difference between the mean \pm one standard deviation values. It should be noted that as seismic response analyses were performed only up to $0.825 \mathrm{~g} P G A$ (there was no interest in the seismic response of the system for rarer ground motions). This upper bound $P G A$ value (which has an annual rate of exceedance of $\lambda_{\mathrm{IM}}=4.0 \times 10^{-5}$ ) should be borne in mind when examining the loss hazard results to follow.

Figure 16a and Figure 16b illustrate the deaggregation of the expected direct repair cost for PGA intensities with $10 \%$ and $2 \%$ probabilities of exceedance in 50 years, respectively. It can be seen that the direct repair loss is primarily attributed to damage to the north piles, central pier and liquefaction of the approach embankments. Conversely, the cost to repair damage to the north and south abutments comprise a significantly smaller proportion of the total repair costs. Unlike some previously conducted loss estimation case-studies [e.g. 2], Figure $16 \mathrm{a}$ and Figure $16 \mathrm{~b}$ illustrate that there is a surprisingly small variation in the contribution of the different components at these two different levels of ground motion.

Figure 17a compares the expected downtime as a function of PGA for the four different repair groups and the total bridge downtime. It can be seen that $\mathrm{RG}_{4}$ (approach embankments) are the repair group which is completed first over the entire range of ground motion intensity, with $\mathrm{RG}_{1}$ and $\mathrm{RG}_{3}$ taking the longest to complete over the majority of $P G A$ values of interest. Figure $17 \mathrm{~b}$ illustrates the dispersion (i.e. lognormal standard deviation) in the repair group downtimes as a function of $P G A$. As has been noted by others in regard to direct repair cost $[29,30]$, the dispersion in the repair group downtime decreases with 
increasing expected downtime values. Also, as mentioned in the previous section, it is noted that the expected total downtime is significantly larger than the expected downtime of the four repair groups, while the dispersion in the total downtime is less than that of the individual repair groups.

Figure 18a and Figure 18b illustrate the deaggregation of the repair group downtime at the PGA intensities with $10 \%$ and $2 \%$ probability of exceedance in 50 years, respectively. It can be seen that as noted in regard to Figure 17, repair of the approach embankments is not critical for either of these PGA intensities. It is worthy of note that Figure 18a illustrates the total repair time for $\mathrm{RG}_{2}$ (in particular, the central pier), is small considering the significance of the central pier in the deaggregation of the direct repair costs (e.g. Figure 16). This is because, as noted in Table 4, the duration required to repair cracking (using epoxy injection) in the central pier does not require excavation of the gravel backfills as in the case of repairing cracking in the bridge abutments. As for the direct repair cost, the downtime to repair damage in the north piles is larger than that for the central and south piles. The time to re-establish adequate seating length of the bridge deck at both the north and south abutments is also an important contributor to the total expected downtime of the bridge-foundation-soil system.

\section{Loss hazard results}

By combining the distribution of loss given ground motion intensity with the ground motion hazard, the annual rate of exceeding some level of loss can be computed as:

$$
\lambda_{L}(l)=\int G_{L \mid I M}(l \mid i m)\left|\frac{d \lambda_{I M}(i m)}{d I M}\right| d I M
$$

where $\lambda_{L}(l)$ is the annual rate of the loss, $L$, exceeding $l, G_{L \mid I M}(l \mid i m)$ is the probability of $L>l$ given $I M=i m$, and $\lambda_{I M}(i m)$ is the ground motion hazard (i.e. Figure 3a). $G_{L \mid I M}(l \mid i m)$ is obtained based on the statistical moments of the $L \mid I M$ distributions obtained in the previous section and using the common assumption of lognormality for $L \mid I M[27,29]$ (which was 
verified for this particular case-study, but is omitted for brevity).

Figure 19 illustrates the annual rate of exceeding various levels of downtime for the four different repair groups and for the total system. While the cracking damage state in the central pier is the primary contributor to the total downtime for values of less than 10 days, for more significant events, the total downtime is predominantly due to $R G_{1}$ and $R G_{3}$.

Knowing that travel delay and vehicle running costs due to inoperability of the bridge structure amount to $\$ 10,720 /$ day [26] (assumed to be a deterministic value), the annual rate of exceeding a specified level of downtime (in days) can be converted to the annual rate of exceeding a specified level of economic loss. Figure 20 illustrates the annual rate of exceeding some level of economic loss due to inoperability of the bridge, as well as the annual rate of exceeding some level of direct repair cost of the system. It can be seen that over the full range of economic losses (or annual rates of exceedance), the economic implications due to loss of functionality is significantly larger than that due to direct repair of damage. In particular, the $10 \%$ in 50 year exceedance probability $\left(\lambda_{L}=2.1 \times 10^{-3}\right)$ direct repair and loss of functionality losses are $\$ 0.475 \mathrm{M}$ and $\$ 2.03 \mathrm{M}$, while the $2 \%$ in 50 year exceedance probability $\left(\lambda_{L}=4.0 \times 10^{-4}\right)$ losses are $\$ 1.20 \mathrm{M}$ and $\$ 3.95 \mathrm{M}$ respectively. For comparative purposes it is again noted that the book-value of the Fitzgerald Avenue twin bridges is only $\$ 2.4 \mathrm{M}$. Thus, there is a $2 \%$ in 50 year probability that the total loss will exceed almost $\$ 5.2 \mathrm{M}$, over twotimes the book-value of the infrastructure itself.

\section{CONCLUSIONS}

This paper has presented a holistic seismic performance and loss assessment of the Fitzgerald Avenue Twin bridges, located on a major arterial route of Christchurch, New Zealand. A finite element model of the longitudinal direction of the bridge-foundation-soil system was constructed, and detailed deterministic seismic effective stress analyses were used to gain considerable insight into the complex seismic response of the system involving 
significant nonlinear dynamic soil behaviour and soil-structure-interaction. Based on the information that they provide such detailed deterministic analyses should always accompany a subsequent probabilistic assessment of seismic performance.

To explicitly account for the uncertainty in the intensity and other characteristics of earthquake-induced ground motions, 20 different input ground motion records were selected based on seismic hazard deaggregation for each of the nine different PGA levels considered. The statistics of the seismic response due to multiple ground motions at various levels of $P G A$ were combined with the $P G A$ ground motion hazard to obtain the annual rate of exceeding various levels of seismic demand for various components of the bridge-foundation-soil system.

Fragility functions for various damage states of the system components were developed, and professional cost estimates were obtained in terms of direct repair cost and repair duration for each of these damage states. A detailed probabilistic seismic loss assessment of the bridge-foundation-soil system was performed. Through the use of loss deaggregation it was determined that the north piles, central pier, deck seating, and approach embankments are the most vulnerable components of the system. The consequences due to loss of functionality of the bridge during repair were significantly larger than the direct repair costs. The fact that there is a $2 \%$ in 50 year probability of combined direct repair and loss of functionality costs exceeding $\$ 5.2 \mathrm{M}$, more than two times the $\$ 2.4 \mathrm{M}$ book-value of the asset, indicates the significant level of risk that seismic hazards pose to this infrastructure.

\section{ACKNOWLEDGEMENTS}

Financial support from the New Zealand Tertiary Education Commission and the New Zealand Earthquake Commission as well as assistance in obtaining cost estimation data from Mr. Lloyd Greenfield (Christchurch City Council) and Mr. William Hopkins (Hopkins Engineering) are greatly appreciated. 


\section{REFERENCES:}

[1] Aslani H, Probabilistic earthquake loss estimation and loss disaggregation in buildings, Ph.D. Thesis, John A. Blume Earthquake Engineering Centre, Dept. of Civil and Environmental Engineering Stanford University, Stanford, CA, 2005, 382.

[2] Bradley BA, Dhakal RP, Cubrinovski M, MacRae GA, Lee DS, Seismic loss estimation for efficient decision making, Bulletin of the New Zealand Society for Earthquake Engineering, 2009;42(2):96-110.

[3] Goulet CA, Haselton CB, Mitrani-Reiser J, Beck JL, Deierlein GG, Porter K, et al., Evaluation of the seismic performance of a code-conforming reinforced-concrete frame building - from seismic hazard to collapse safety and economic losses, Earthquake Eng. Struct. Dyn., 2007;36(13):1973-1997.

[4] Cornell CA, and Krawinkler H, Progress and challenges in seismic performance assessment, PEER Center News, 2000;3(2):1-3.

[5] Porter KA, Kiremidjian AS, LeGrue JS, Assembly-based vulnerability for buildings and its use in performance evaluation, Earthquake Spectra, 2001;17(2):291-312.

[6] Tonkin and Taylor Ltd, Fitzgerald Avenue bridge geotechnical investigation factual report. Prepared for Christchurch City Council, 2006,

[7] Diana-J3: Finite-element program for effective stress analysis of two-phase soil medium. Software science, 1987, Taisei Corporation internal report 1997 [in Japanese]

[8] Bowen H, and Cubrinovski M, Effective stress analysis of piles in liquefiable soil: A case study of a bridge foundation, Bulletin of the New Zealand Society for Earthquake Engineering, 2008;41(4):247-262.

[9] Cubrinovski M, and Bradley BA, Evaluation of seismic performance of geotechnical structures, in International Conference on Performance-Based Design in Earthquake Geotechnical Engineering - from case history to practice, Tokyo, Japan, 2009 p. 16

[10] Cubrinovski M, and Ishihara K, Modelling of sand behaviour based on state concept, Soils and Foundations, 1998;28(3):115-127.

[11] Cubrinovski M, and Ishihara K, State concept and modified elastoplasticity for sand modelling, Soils and foundations, 1998;38(4):213-225.

[12] Ishihara K, Liquefaction and flow failure during earthquakes, 33rd Rankine Lecture, Geotechnique, 1993;43(3):351-415.

[13] Cubrinovski M, Uzuoka R, Sugita H, Tokimatsu K, Sato M, Ishihara K, et al., Prediction of pile response to lateral spreading by 3-D soil-water coupled dynamic analysis: shaking in the direction of ground flow, Soil Dyn. Earthquake Eng., 2008;28(6):421435.

[14] Kramer SL, Geotechnical earthquake engineering. Upper Saddle River, NJ.: PrenticeHall, 1996.

[15] Cornell CA, Engineering seismic risk analysis, Bull. Seism. Soc. Am., 1968;58(5):1583-1606.

[16] Bradley BA, Cubrinovski M, Dhakal RP, MacRae GA, Intensity measures for the seismic response of pile foundations, Soil Dyn. Earthquake Eng., 2009;29(6):10461058 . 
[17] Bradley BA, Cubrinovski M, MacRae GA, Dhakal RP, Ground motion prediction equation for spectrum intensity from spectral acceleration relationships, Bull. Seism. Soc. Am., 2009;99(1):277-285.

[18] Boore DM, and Atkinson GM, Ground-motion prediction equations for the average horizontal component of PGA, PGV, and 5\%-damped PSA at spectral periods between 0.01s and 10.0s, Earthquake Spectra, 2008;24(1):99-138.

[19] Baker JW, and Cornell CA, Spectral shape, record selection and epsilon, Earthquake Eng. Struct. Dyn., 2006;35(9):1077-1095.

[20] Shome N, and Cornell CA, Probabilistic seismic demand analysis of nonlinear structures, Stanford University, Stanford, CA Report No. RMS-35, RMS Program, 1999, 357.

[21] Stirling MW, Gerstenberger M, Litchfield N, McVerry GH, Smith WD, Pettinga JR, et al., Updated probabilistic seismic hazard assessment for the Canterbury region, 2007, 58.

[22] Power M, Chiou B, Abrahamson NA, Bozorgnia Y, Shantz T, Roblee C, An overview of the NGA project, Earthquake Spectra, 2008;24(1):3-21.

[23] Luco N, and Bazzurro P, Does amplitude scaling of ground motion records result in biased nonlinear structural drift responses?, Earthquake Eng. Struct. Dyn., 2007;36(13):1813-1835.

[24] Boore DM, Watson-Lamprey J, Abrahamson NA, Orientation-independent measures of ground motion, Bull. Seism. Soc. Am., 2006;96(4A):1502-1511.

[25] Hopkins W, Cost estimates for seismic damage to the Fitzgerald Avenue twin bridges, 2009, p. (personal communication).

[26] MWH, Avonside/Fitzgerald/Kilmore Intersection: Economic Evaluation, Prepared for: Christchurch City Council 2008, 42.

[27] Bradley BA, and Lee DS, Correlations in structure-specific seismic loss estimation, Earthquake Eng. Struct. Dyn., 2009:(in press).

[28] Mitrani-Reiser J, An ounce of prevention: Probabilistic loss estimation for performance-based earthquake engineering, Ph.D. Thesis, California Institute of technology, Pasadena, CA, 2007, 173.

[29] Krawinkler H, Van Nuys hotel building testbed report: exercising seismic performance assessment. PEER 2005/11 Pacific Earthquake Engineering Research Centre 2005, 264.

[30] Bradley BA, Dhakal RP, Cubrinovski M, MacRae GA, Prediction of spatially distributed seismic demands in structures: from structural response to loss estimation, Earthquake Eng. Struct. Dyn., 2009:(in press). 
Table 1: Pile and superstructure model properties.

\begin{tabular}{|c|c|c|c|}
\hline Structural element & $\begin{array}{c}M_{C}, M_{Y}, M_{U} \\
(\mathrm{MN}-\mathrm{m})\end{array}$ & $\begin{array}{c}\phi_{C}, \phi_{Y}, \phi_{U} \\
(1 / \mathrm{m})\end{array}$ & $\begin{array}{c}E I, M_{F}{ }^{1} \\
\left(\mathrm{MN}-\mathrm{m}^{2}\right)(\mathrm{MN}-\mathrm{m})\end{array}$ \\
\hline $1.2 \mathrm{~m}$ diameter pile & $1.25,4.22,6.74$ & $0.0003,0.0018,0.009$ & $4.1 \times 10^{3}, 7.70$ \\
\hline 1.5 m diameter pile & $2.75,7.50,12.0$ & $0.0005,0.0015,0.009$ & $9.7 \times 10^{3}, 14.0$ \\
\hline Bridge pier & $1.58,4.91,6.50$ & $0.00055,0.0036,0.01$ & $3.6 \times 10^{3}, 7.91$ \\
\hline Bridge deck & - & - & $3.99 \times 10^{3}$ \\
\hline
\end{tabular}

${ }^{1} E I, M_{F}$ values are those used in the hyperbolic moment-curvature model.

${ }^{2}$ Bridge deck modeled as linear elastic.

Table 2: Ground motion intensity levels and their rate of exceedance.

\begin{tabular}{|c|c|c|c|}
\hline IM level & $P G A$ & $\mathrm{P}(P G A>p g a \mid 50 \mathrm{yr})$ & $\lambda_{P G A}$ \\
\hline 1 & 0.0834 & 0.8 & $3.22 \times 10^{-2}$ \\
\hline 2 & 0.125 & 0.5 & $1.39 \times 10^{-2}$ \\
\hline 3 & 0.205 & 0.2 & $4.46 \times 10^{-3}$ \\
\hline 4 & 0.276 & 0.1 & $2.11 \times 10^{-3}$ \\
\hline 5 & 0.355 & 0.05 & $1.03 \times 10^{-3}$ \\
\hline 6 & 0.463 & 0.02 & $4.04 \times 10^{-4}$ \\
\hline 7 & 0.562 & 0.01 & $2.01 \times 10^{-4}$ \\
\hline 8 & 0.671 & 0.005 & $1.00 \times 10^{-4}$ \\
\hline 9 & 0.825 & 0.002 & $4.00 \times 10^{-5}$ \\
\hline
\end{tabular}


Table 3: Ground motions used in the seismic effective stress analyses.

\begin{tabular}{|c|c|c|c|c|c|c|c|c|}
\hline $\mathrm{ID}^{1}$ & Event & Year & Station & $M$ & $\begin{array}{c}R \\
(\mathrm{~km})\end{array}$ & $\begin{array}{c}V_{s 30} \\
(\mathrm{~m} / \mathrm{s})\end{array}$ & $\begin{array}{c}P G A \\
(\mathrm{~g})\end{array}$ & IM level \\
\hline 15 & Kern County & 1952 & Taft Lincoln School & 7.36 & 38.89 & 385.4 & 0.173 & 3 \\
\hline 33 & Parkfield & 1966 & Temblor pre-1969 & 6.19 & 16.24 & 527.9 & 0.293 & 4,5 \\
\hline 57 & San Fernando & 1971 & Castaic - Old Ridge Route & 6.61 & 22.63 & 450.3 & 0.299 & 6 \\
\hline 68 & & & LA - Hollywood Stor FF & 6.61 & 25.89 & 316.5 & 0.210 & 4 \\
\hline 77 & & & Pacoima Dam (left abut) & 6.61 & 3.03 & 2016.1 & 1.164 & 9 \\
\hline 154 & Coyote Lake & 1979 & San Juan Bautista, 24 Polk St & 5.74 & 19.70 & 370.8 & 0.101 & 1,2 \\
\hline 189 & Imperial Valley-06 & 1979 & SAHOP Casa Flores & 6.53 & 10.79 & 338.6 & 0.357 & 6 \\
\hline 231 & Mammoth Lakes-01 & 1980 & Long Valley Dam (L Abut) & 6.06 & 15.46 & 345.4 & 0.340 & 5 \\
\hline 265 & Victoria, Mexico & 1980 & Cerro Prieto & 6.33 & 14.37 & 659.6 & 0.572 & 7 \\
\hline 316 & Westmorland & 1981 & Parachute Test Site & 5.90 & 16.81 & 348.7 & 0.219 & 3,4 \\
\hline 318 & & & Superstition Mtn Camera & 5.90 & 19.50 & 362.4 & 0.101 & 1,2 \\
\hline 359 & Coalinga-01 & 1983 & Parkfield - Vineyard Cany 1E & 6.36 & 26.38 & 338.5 & 0.182 & 3 \\
\hline 450 & Morgan Hill & 1984 & Corralitos & 6.19 & 23.43 & 462.2 & 0.098 & 1,2 \\
\hline 534 & N. Palm Springs & 1986 & San Jacinto - Soboba & 6.06 & 23.31 & 370.8 & 0.231 & 3,4 \\
\hline 552 & Chalfant Valley- 02 & 1986 & Lake Crowley - Shehorn Res. & 6.19 & 24.47 & 338.5 & 0.123 & 1,2 \\
\hline 553 & & & Long Valley Dam (Downst) & 6.19 & 21.12 & 345.4 & 0.075 & 1 \\
\hline 598 & Whittier Narrows-01 & 1987 & Big Tujunga, Angeles Nat F & 5.99 & 28.50 & 446.0 & 0.149 & $1,2,3$ \\
\hline 600 & & & Brea Dam (Downstream) & 5.99 & 23.99 & 370.8 & 0.231 & 4 \\
\hline 611 & & & Compton - Castlegate St & 5.99 & 23.37 & 308.6 & 0.331 & 5 \\
\hline 625 & & & Inglewood - Union Oil & 5.99 & 25.86 & 316.0 & 0.263 & 3,4 \\
\hline 626 & & & LA - 116th St School & 5.99 & 23.29 & 301.0 & 0.341 & 4,5 \\
\hline 638 & & & LA - N Westmoreland & 5.99 & 21.11 & 315.1 & 0.201 & 3 \\
\hline 641 & & & LA - Saturn St & 5.99 & 24.99 & 308.7 & 0.123 & 1,2 \\
\hline 692 & & & Santa Fe Springs - E.Joslin & 5.99 & 18.49 & 308.6 & 0.433 & $5,6,7$ \\
\hline 727 & Superstition Hills-02 & 1987 & Superstition Mtn Camera & 6.54 & 6.56 & 362.4 & 0.793 & 8,9 \\
\hline 767 & Loma Prieta & 1989 & Gilroy Array \#3 & 6.93 & 12.82 & 349.9 & 0.462 & $6,7,8$ \\
\hline 770 & & & Gilroy Array \#7 & 6.93 & 22.68 & 333.9 & 0.312 & 4,5 \\
\hline 776 & & & Hollister - South \& Pine & 6.93 & 27.93 & 370.8 & 0.279 & 5 \\
\hline 779 & & & LGPC & 6.93 & 3.88 & 477.7 & 0.784 & 8,9 \\
\hline 810 & & & UCSC Lick Observatory & 6.93 & 18.41 & 714.0 & 0.457 & 7 \\
\hline 811 & & & WAHO & 6.93 & 17.47 & 376.1 & 0.517 & 7,8 \\
\hline 828 & Cape Mendocino & 1992 & Petrolia & 7.01 & 8.18 & 712.8 & 0.624 & 8,9 \\
\hline 830 & & & Shelter Cove Airport & 7.01 & 28.78 & 513.7 & 0.195 & 2,3 \\
\hline 838 & Landers & 1992 & Barstow & 7.28 & 34.99 & 370.8 & 0.119 & 1,2 \\
\hline 879 & & & Lucerne & 7.28 & 3.71 & 684.9 & 0.721 & 9 \\
\hline 900 & & & Yermo Fire Station & 7.28 & 23.80 & 353.6 & 0.223 & 3,4 \\
\hline 952 & Northridge- 01 & 1994 & Beverly Hills - 12520 Mulhol & 6.69 & 18.36 & 545.7 & 0.510 & 7,8 \\
\hline 963 & & & Castaic - Old Ridge Route & 6.69 & 20.72 & 450.3 & 0.490 & $5,6,7$ \\
\hline 982 & & & Jensen Filter Plant & 6.69 & 5.43 & 373.1 & 0.764 & 9 \\
\hline 983 & & & Jensen Filter Plant Generator & 6.69 & 5.43 & 525.8 & 0.765 & 9 \\
\hline 991 & & & LA - Cypress Ave & 6.69 & 30.70 & 446.0 & 0.206 & 4 \\
\hline 995 & & & LA - Hollywood Stor FF & 6.69 & 24.03 & 316.5 & 0.335 & 6 \\
\hline 998 & & & LA - N Westmoreland & 6.69 & 26.73 & 315.1 & 0.370 & 5,6 \\
\hline 999 & & & LA - Obregon Park & 6.69 & 37.36 & 349.4 & 0.467 & 6,7 \\
\hline 1001 & & & LA - S Grand Ave & 6.69 & 33.99 & 308.6 & 0.273 & 5 \\
\hline 1003 & & & LA - Saturn St & 6.69 & 27.01 & 308.7 & 0.454 & 6,7 \\
\hline 1004 & & & LA - Sepulveda VA Hospital & 6.69 & 8.44 & 380.1 & 0.803 & 9 \\
\hline 1007 & & & LA - Univ. Hospital & 6.69 & 34.20 & 376.1 & 0.349 & 6 \\
\hline 1054 & & & Pardee - SCE & 6.69 & 7.46 & 345.4 & 0.505 & 8 \\
\hline 1077 & & & Santa Monica City Hall & 6.69 & 26.45 & 336.2 & 0.591 & 7,8 \\
\hline 1080 & & & Simi Valley - Katherine Rd & 6.69 & 13.42 & 557.4 & 0.745 & 8,9 \\
\hline 1085 & & & Sylmar - Converter Sta East & 6.69 & 5.19 & 370.5 & 0.647 & 8,9 \\
\hline 1643 & Sierra Madre & 1991 & LA - City Terrace & 5.61 & 25.69 & 365.2 & 0.102 & 1,2 \\
\hline 1647 & & & San Marino - SW Academy & 5.61 & 18.74 & 379.4 & 0.144 & $1,2,3$ \\
\hline
\end{tabular}

${ }^{1}$ As given in the NGA database. http://peer.berkeley.edu/nga/earthquakes.html 
Table 4: Damage states of components with fragility and loss data.

\begin{tabular}{|c|c|c|c|c|c|}
\hline Component & Damage State & $\begin{array}{l}\text { Fragility } \\
\mu_{E D P \mid D S} \\
\sigma_{\ln E D P \mid D S}\end{array}$ & Repair & $\begin{array}{c}\text { Repair cost }(\$ \mathrm{M}) \\
\mu_{L_{R C} \mid D S} \\
\sigma_{\ln L_{R C} \mid D S}\end{array}$ & \begin{tabular}{|c|} 
Repair duration \\
(days) \\
$\mu_{L_{D T} \mid D S}$ \\
$\sigma_{\ln L_{D T} \mid D S}$ \\
\end{tabular} \\
\hline \multirow[b]{3}{*}{$\begin{array}{l}1.2 \mathrm{~m} \text { diameter } \\
\text { pile }\end{array}$} & Cracking & $0.0003 / \mathrm{m}, 0.15$ & None & $0.0,0.0$ & $0.0,0.0$ \\
\hline & Yielding & $0.0018 / \mathrm{m}, 0.25$ & $\begin{array}{l}\text { Replace pile with fixed } \\
\text { connection to pile cap }\end{array}$ & $0.18,0.40$ & $120.0,0.40$ \\
\hline & Failure & $0.0060 / \mathrm{m}, 0.50$ & $\begin{array}{l}\text { Loss of vertical carrying } \\
\text { capacity and significant } \\
\text { settlement. Replace pile and } \\
\text { repair settled abutment }\end{array}$ & $0.48,0.40$ & $180.0,0.40$ \\
\hline \multirow[b]{3}{*}{$\begin{array}{l}1.5 \mathrm{~m} \text { diameter } \\
\text { pile }\end{array}$} & Cracking & $0.0005 / \mathrm{m}, 0.20$ & None & $0.0,0.0$ & $0.0,0.0$ \\
\hline & Yielding & $0.0015 / \mathrm{m}, 0.25$ & $\begin{array}{l}\text { Replace pile with fixed } \\
\text { connection to pile cap }\end{array}$ & $0.20,0.40$ & $120.0,0.40$ \\
\hline & Failure & $0.0060 / \mathrm{m}, 0.50$ & $\begin{array}{l}\text { Loss of vertical carrying } \\
\text { capacity and significant } \\
\text { settlement. Replace pile and } \\
\text { repair settled abutment }\end{array}$ & $0.50,0.40$ & $180.0,0.40$ \\
\hline \multirow{4}{*}{ Abutments } & Cracking & $0.00055 / \mathrm{m}, 0.15$ & $\begin{array}{c}\text { Epoxy injection. Requires } \\
\text { excavation of approach to access }\end{array}$ & $0.02,0.35$ & $90.0,0.35$ \\
\hline & Yielding & $0.0036 / \mathrm{m}, 0.25$ & Externally reinforce & $0.18,0.35$ & $180.0,0.35$ \\
\hline & Spalling/Buckling & $0.0080 / \mathrm{m}, 0.35$ & \begin{tabular}{|c|} 
Replace abutment \\
\end{tabular} & $0.50,0.35$ & $240.0,0.35$ \\
\hline & Axial Failure & $0.0150 / \mathrm{m}, 0.50$ & Replace abutment and deck span & $1.00,0.35$ & $360.0,0.35$ \\
\hline \multirow{4}{*}{ Central pier } & Cracking & $0.00055 / \mathrm{m}, 0.15$ & $\begin{array}{c}\text { Epoxy injection. Requires } \\
\text { excavation of approach to access }\end{array}$ & $0.02,0.35$ & $20.0,0.35$ \\
\hline & Yielding & $0.0036 / \mathrm{m}, 0.25$ & Externally reinforce & $0.18,0.35$ & $180.0,0.35$ \\
\hline & Spalling/Buckling & $0.0080 / \mathrm{m}, 0.35$ & Replace abutment & $0.50,0.35$ & $240.0,0.35$ \\
\hline & Axial Failure & $0.0150 / \mathrm{m}, 0.50$ & Replace abutment and deck span & $1.00,0.35$ & $360.0,0.35$ \\
\hline \multirow[t]{2}{*}{ Deck } & Minor movement & $0.05 \mathrm{~m}, 0.20$ & $\begin{array}{c}\text { Minor repair of expansion joints, } \\
\text { mechanical devices for } \\
\text { additional seating length }\end{array}$ & $0.15,0.40$ & $90.0,0.40$ \\
\hline & Unseating & $0.25 \mathrm{~m}, 0.20$ & $\begin{array}{c}\text { Deck unseats and falls, replace } \\
\text { damaged deck }\end{array}$ & $0.40,0.40$ & $180.0,0.40$ \\
\hline \multirow{2}{*}{$\begin{array}{l}\text { Approach } \\
\text { embankments }\end{array}$} & Minor settlement & $0.10 \mathrm{~m}, 0.30$ & $\begin{array}{c}\text { Cracking of approach road, } \\
\text { requires new subgrade and } \\
\text { basecourse }\end{array}$ & $0.15,0.40$ & $120.0,0.40$ \\
\hline & $\begin{array}{l}\text { Significant } \\
\text { settlement }\end{array}$ & $0.30 \mathrm{~m}, 0.30$ & $\begin{array}{c}\text { Earthworks to increase approach } \\
\text { height and densify soil, new } \\
\text { approach roading }\end{array}$ & $0.60,0.40$ & $180.0,0.40$ \\
\hline
\end{tabular}

Table 5: Repair groups used in the repair duration computations.

\begin{tabular}{|c|c|c|c|}
\hline $\begin{array}{c}\text { RG } \\
\text { number }\end{array}$ & Description & $P G$ 's & Precurssor RG's \\
\hline 1 & North end of bridge & North piles, north abutment, north deck seating & None \\
\hline 2 & Central portion of bridge & Central piles, central pier & None \\
\hline 3 & South end of bridge & South piles, south abutment, south deck seating & None \\
\hline 4 & Approach embankments & North/south approach embankments in parallel & None \\
\hline 5 & Total repair time & None & $R G_{l}, R G_{2}, R G_{3}, R G_{4}$ \\
\hline
\end{tabular}




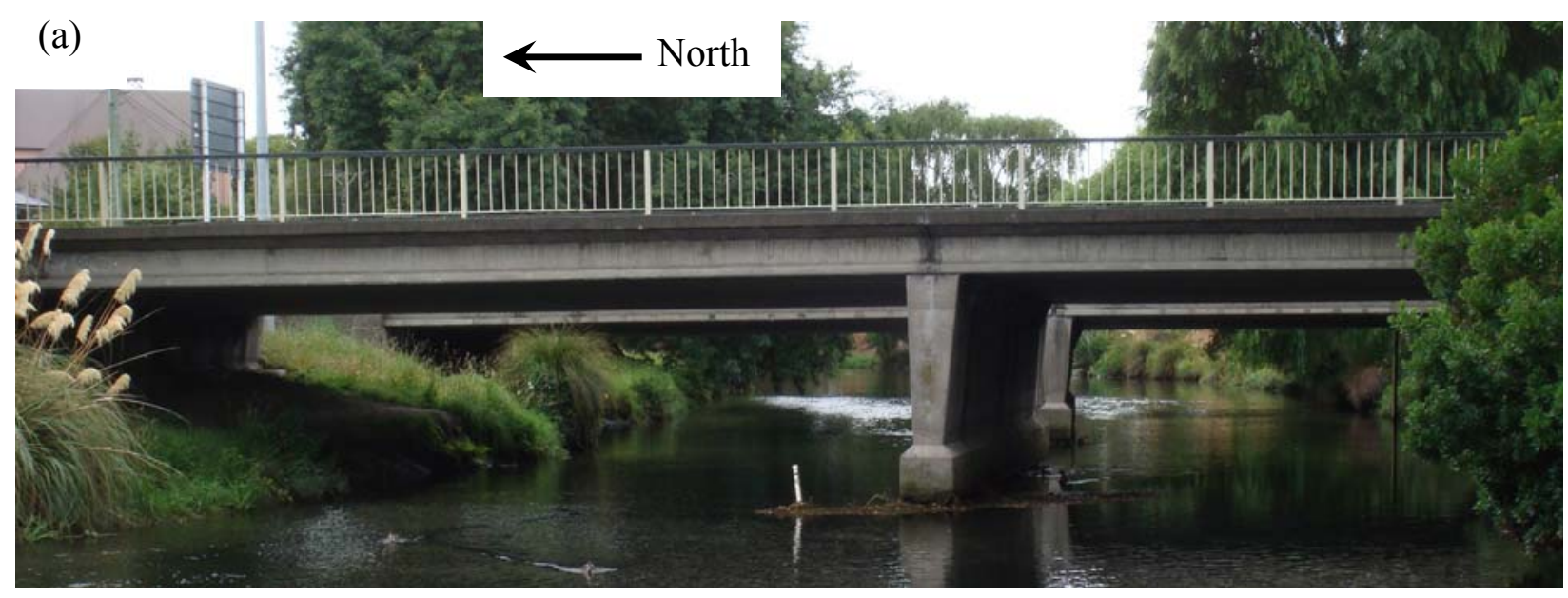

(b)

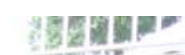

(c)
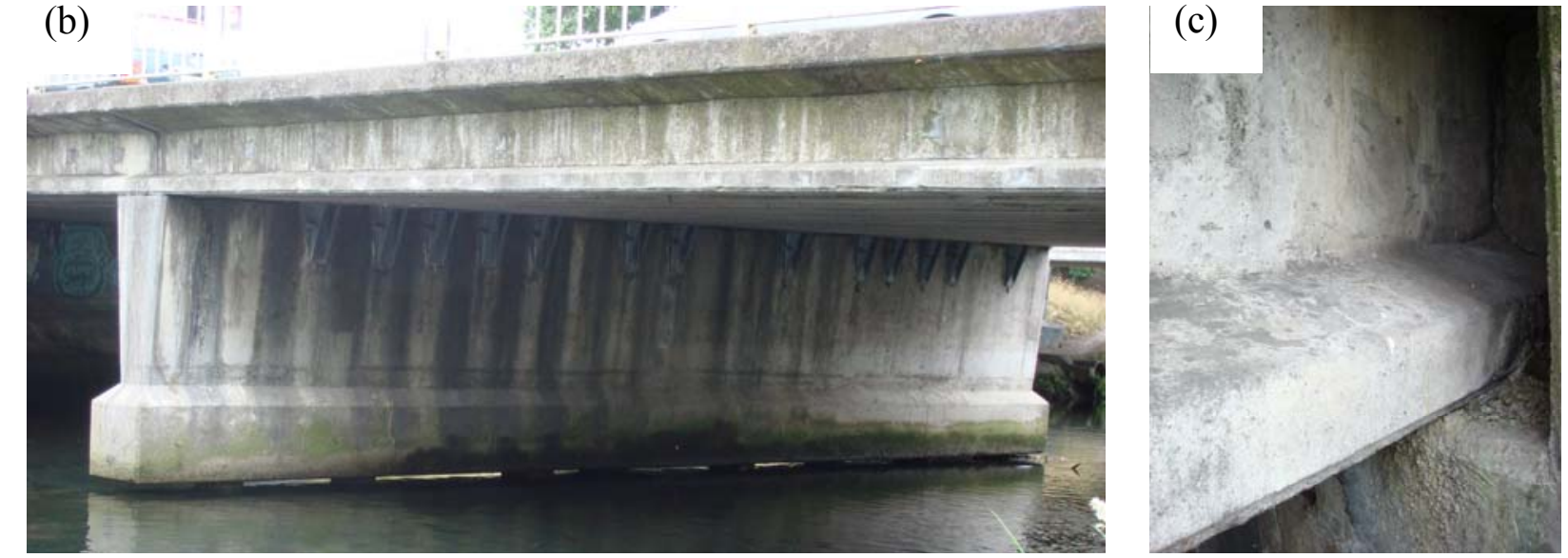

Figure 1: The Fitzgerald Avenue twin bridges: (a) elevation of the west bridge; (b) central pier and pile cap; and (c) seating connection of bridge deck on abutments. North is indicated in the direction right to left. 


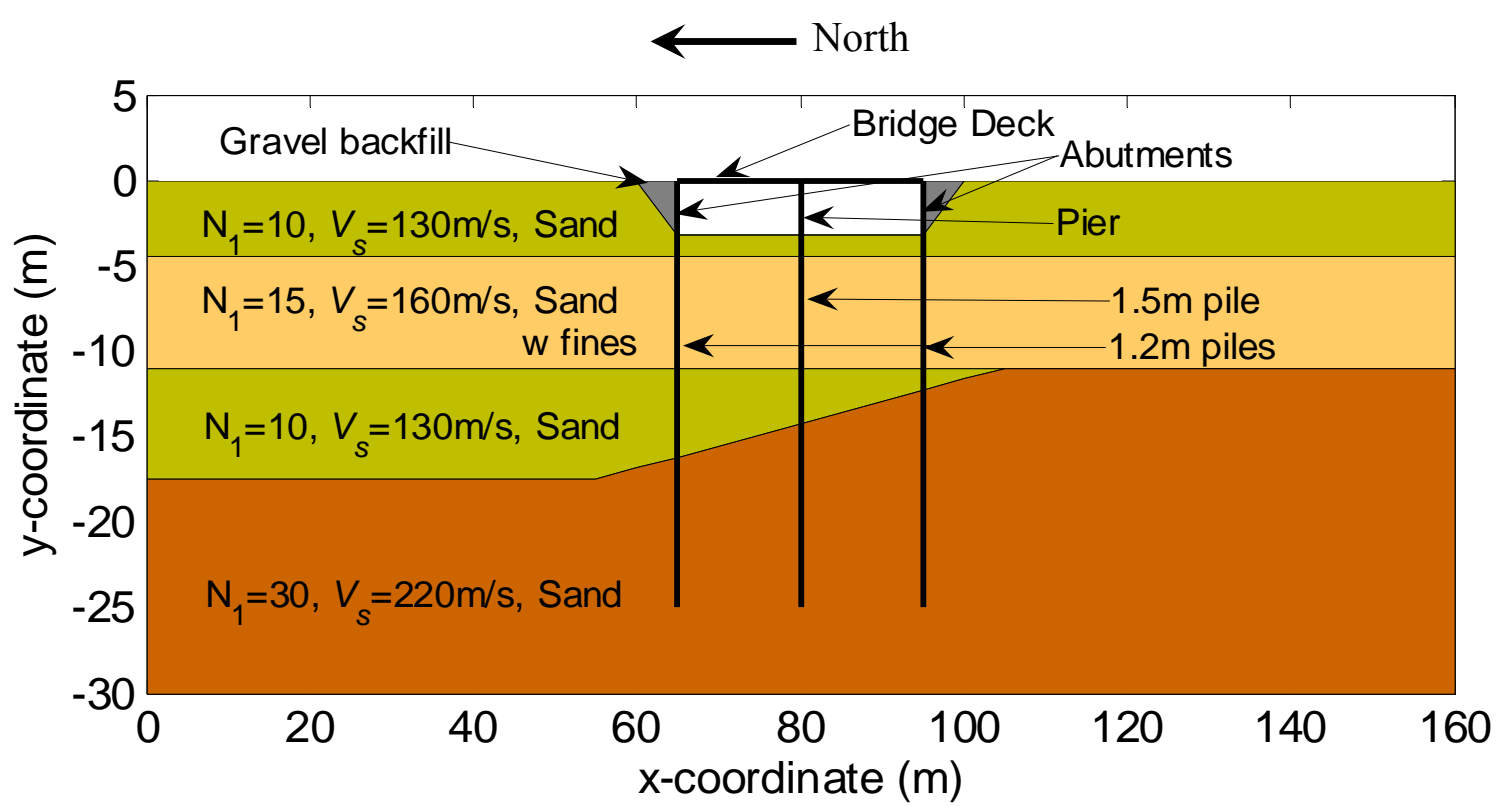

Figure 2: Schematic illustration of computational model. Soil, pile and superstructure properties are given in Table 1. 
(a)

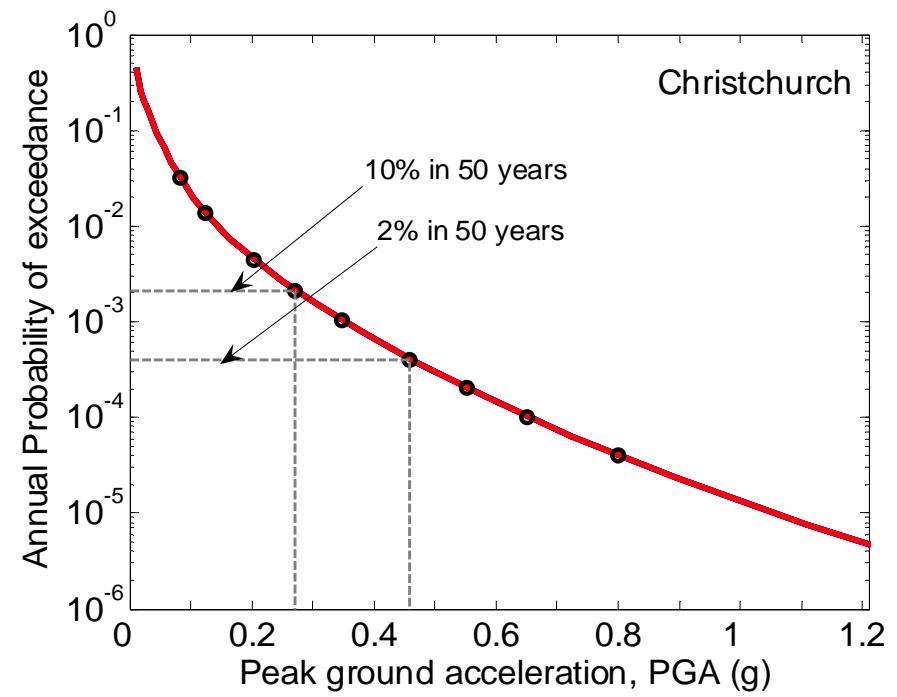

(b)

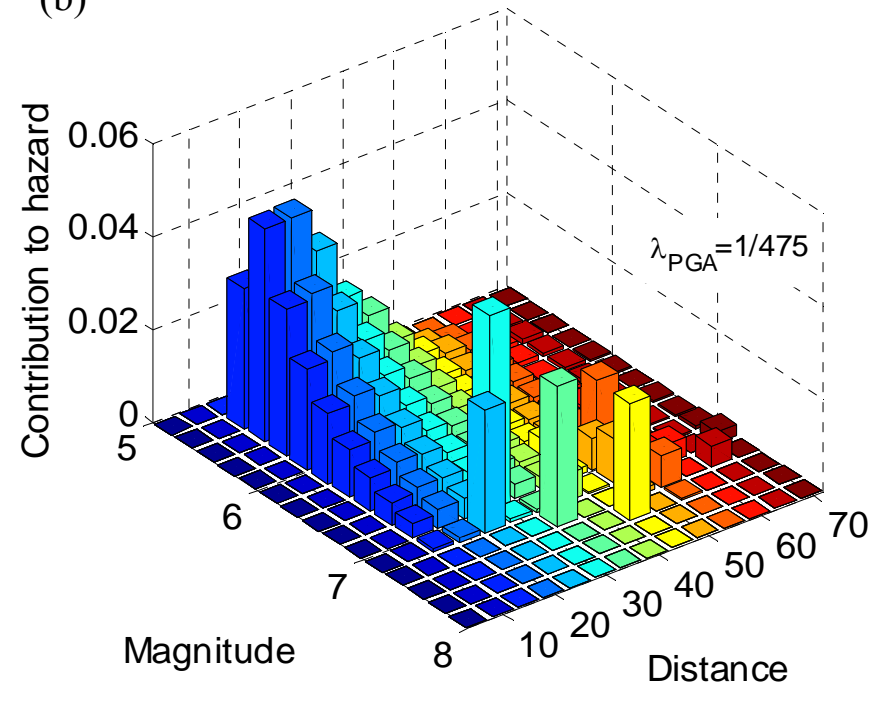

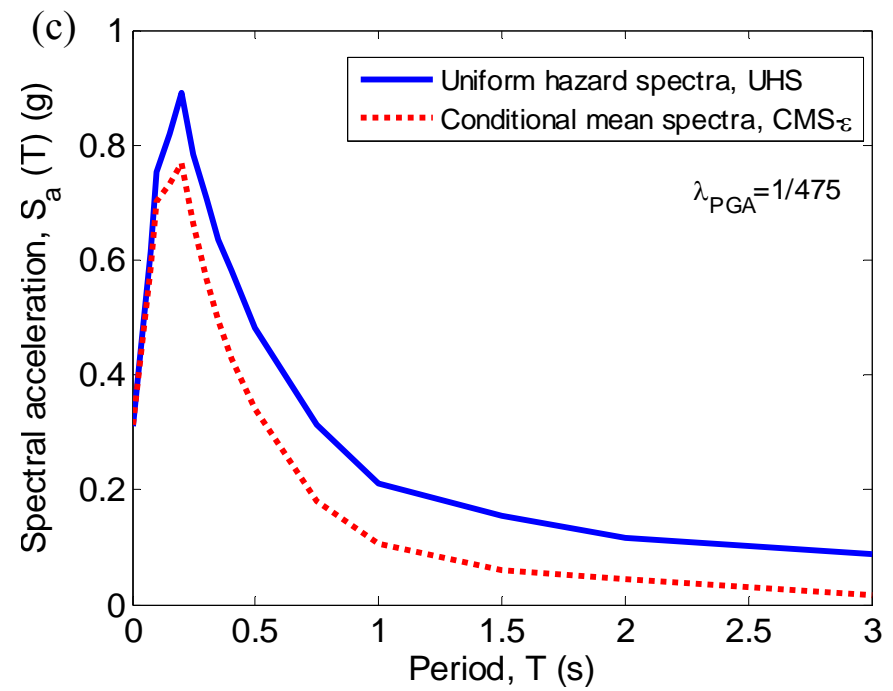

Figure 3: Details of the PGA seismic hazard for class C soil in Christchurch: (a) Seismic hazard curve; (b) Deaggregation of the hazard curve for $\lambda_{P G A}=1 / 475$; and (c) Ground motion target spectra for $\lambda_{P G A}=1 / 475$. 
(a)

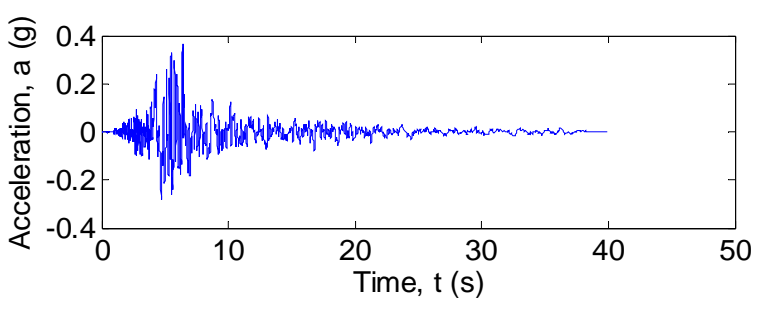

(b)

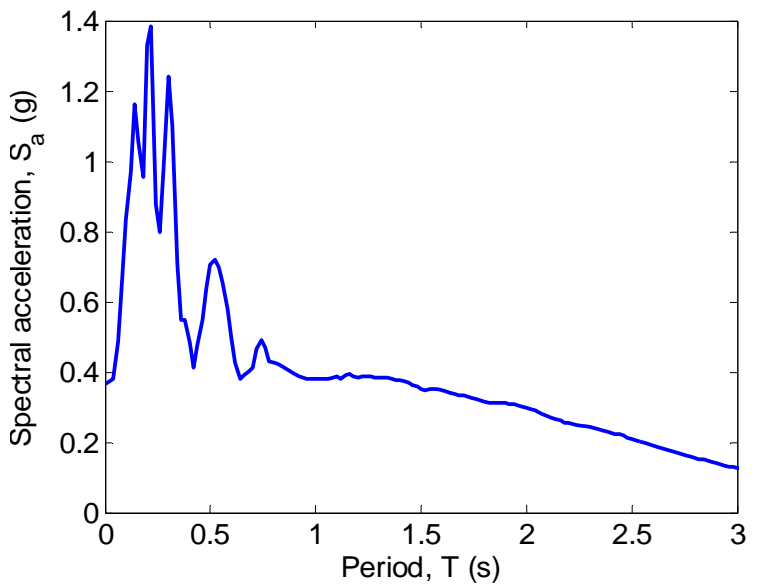

Figure 4: (a) acceleration time-history; and (b) acceleration response spectra of the ground motion used in the deterministic performance assessment. 


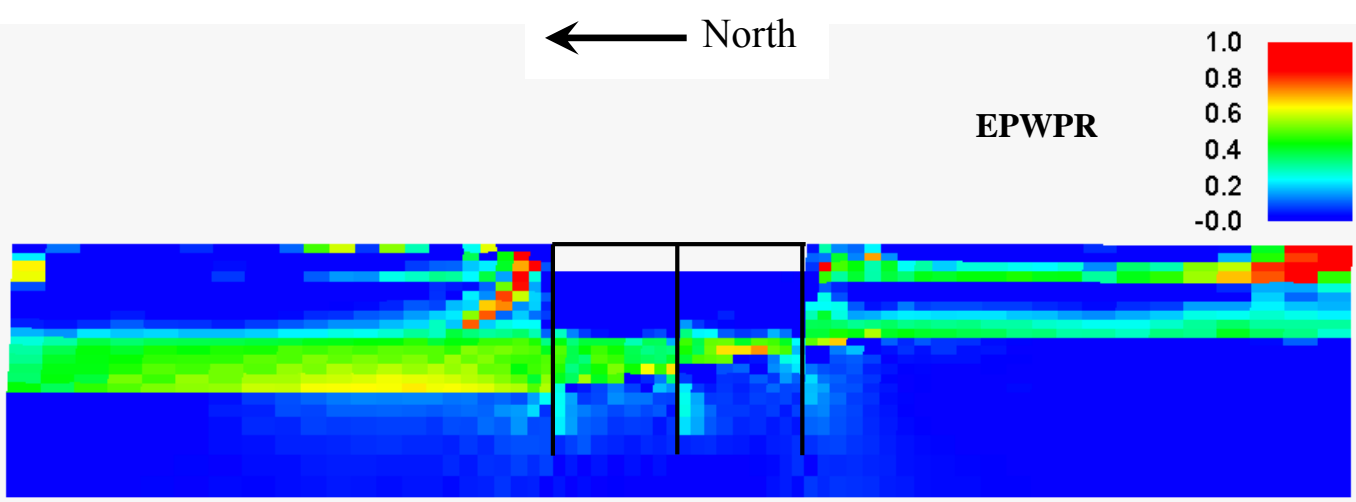

Time : $\mathbf{5} .500$

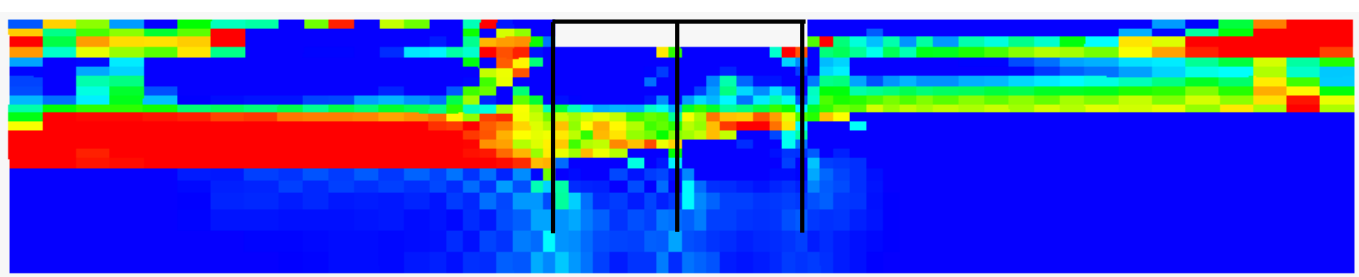

Time : 6.000

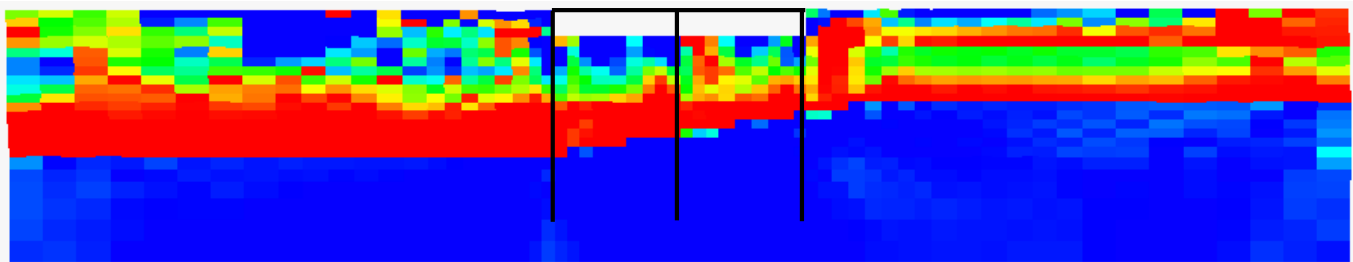

Time : 7.000

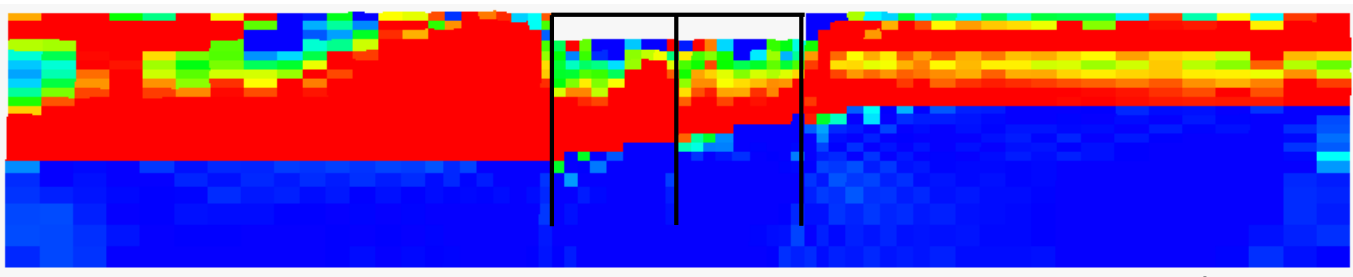

Time : 10.000

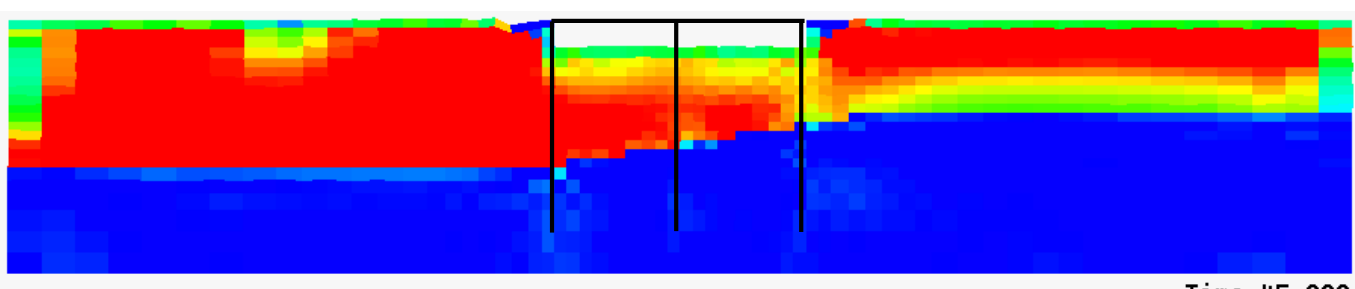

Time: 45.000

Figure 5: Development of excess pore water pressures and eventual liquefaction in the model during the deterministic analysis. Note that an excess pore water pressure ratio (EPWPR) of 1.0 indicates liquefaction and zero effective stress in the soil. 
(a)

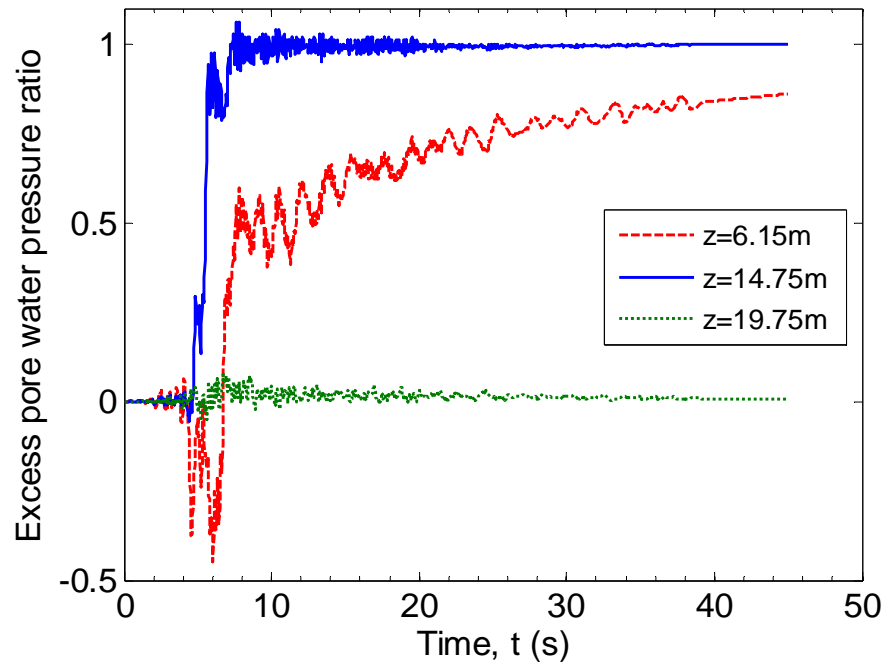

(b)

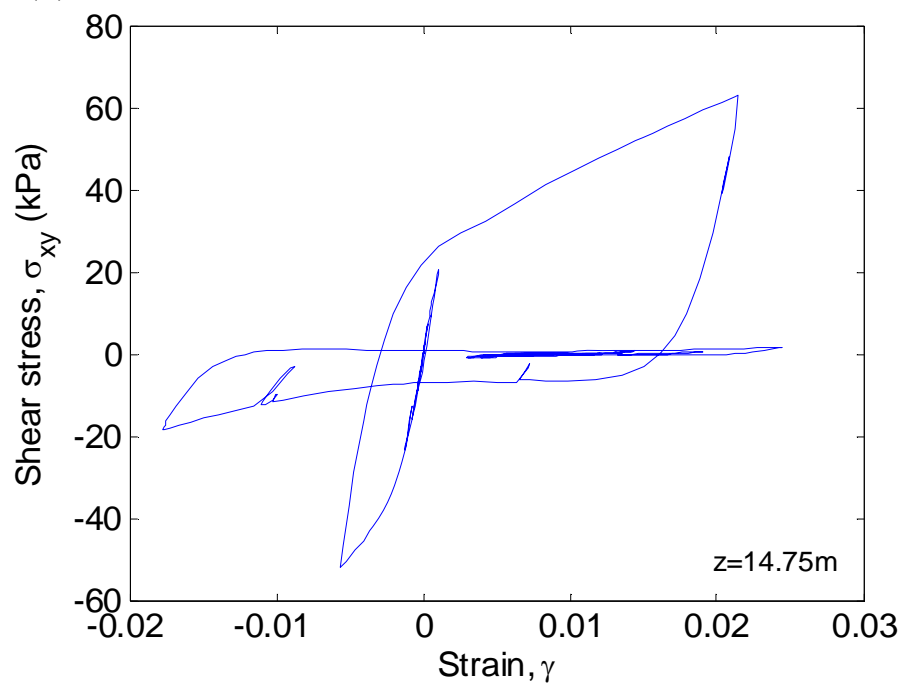

Figure 6: (a) Typical excess pore water pressure ratio development in the north free field ( $x=20 \mathrm{~m}$ in Figure 2) at various depths; and (b) typical shear stressstrain response. 
(a)

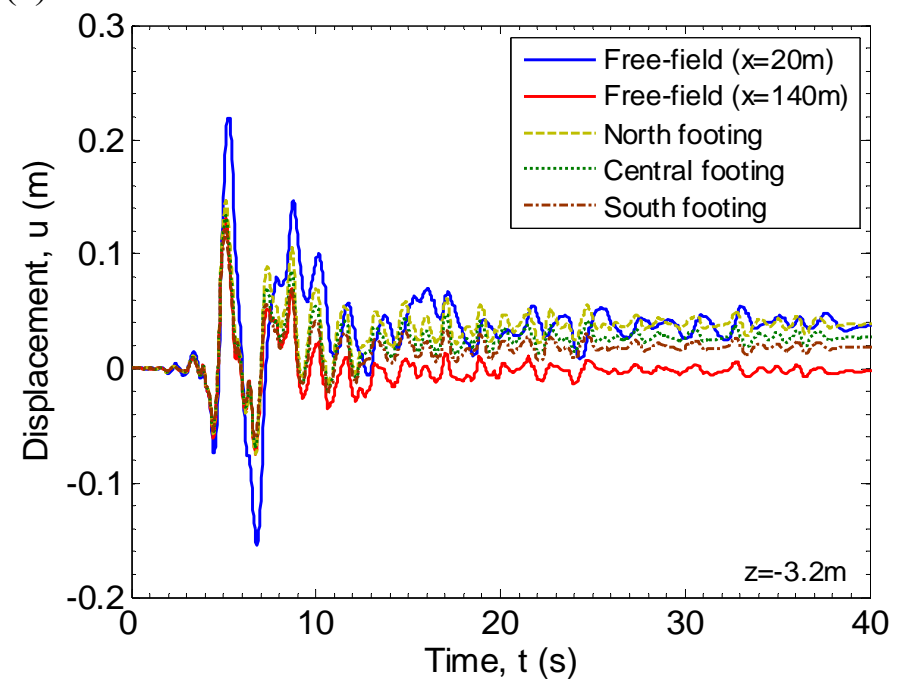

(b)

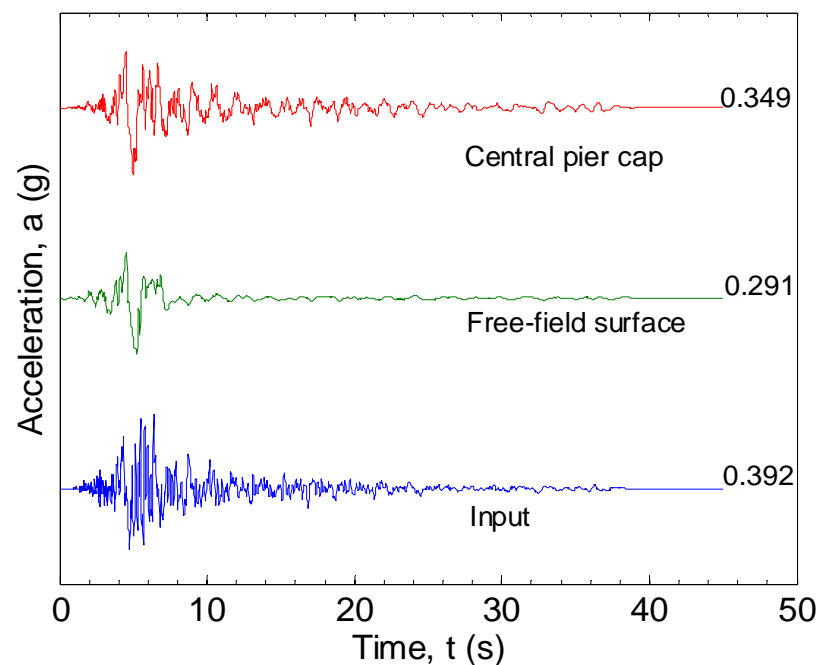

Figure 7: (a) displacement response history of the free field and at the pile footings; and (b) comparison of input, free-field surface, and pier cap acceleration histories (maximum values given at the end of each history). 
(a)

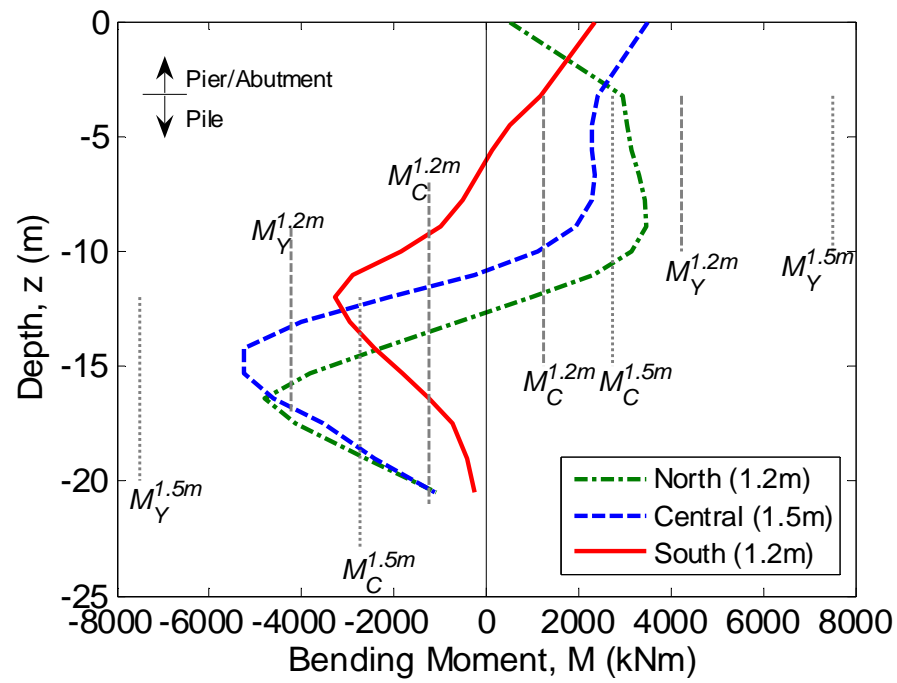

(b)

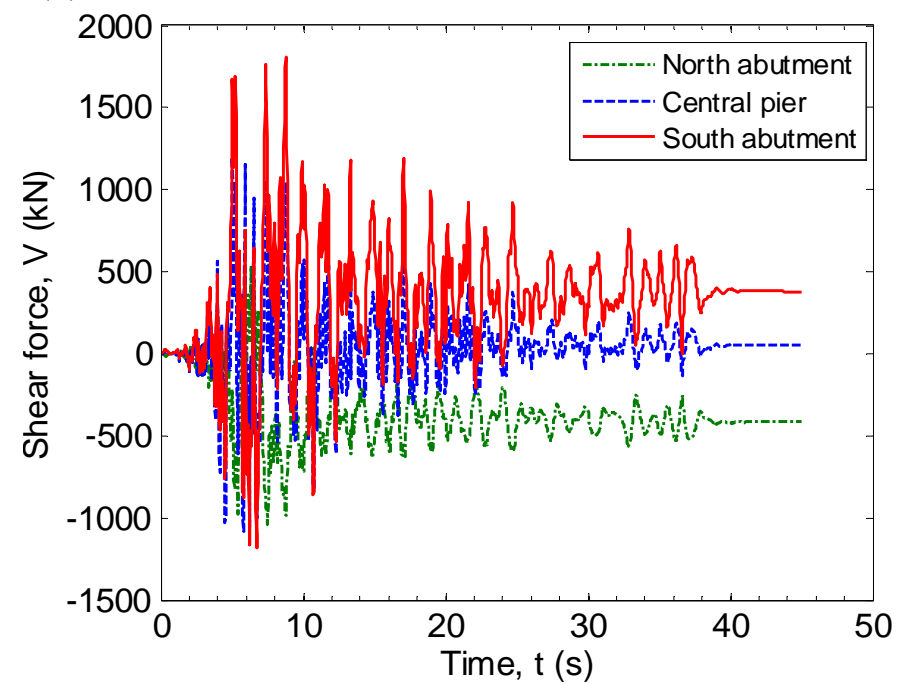

Figure 8: (a) bending moment profiles of the pile foundations at $\mathrm{t}=5.15 \mathrm{~s}$; and

(b) shear force time histories in the abutments/pier. Symbols $M_{C}^{1.2 m}, M_{Y}^{1.2 m}$, $M_{U}^{1.2 m}$, and $M_{C}^{1.5 m}, M_{Y}^{1.5 m}, M_{U}^{1.5 m}$ represent cracking, yielding, and ultimate moment capacities for the $1.2 \mathrm{~m}$ and $1.5 \mathrm{~m}$ piles, respectively. 


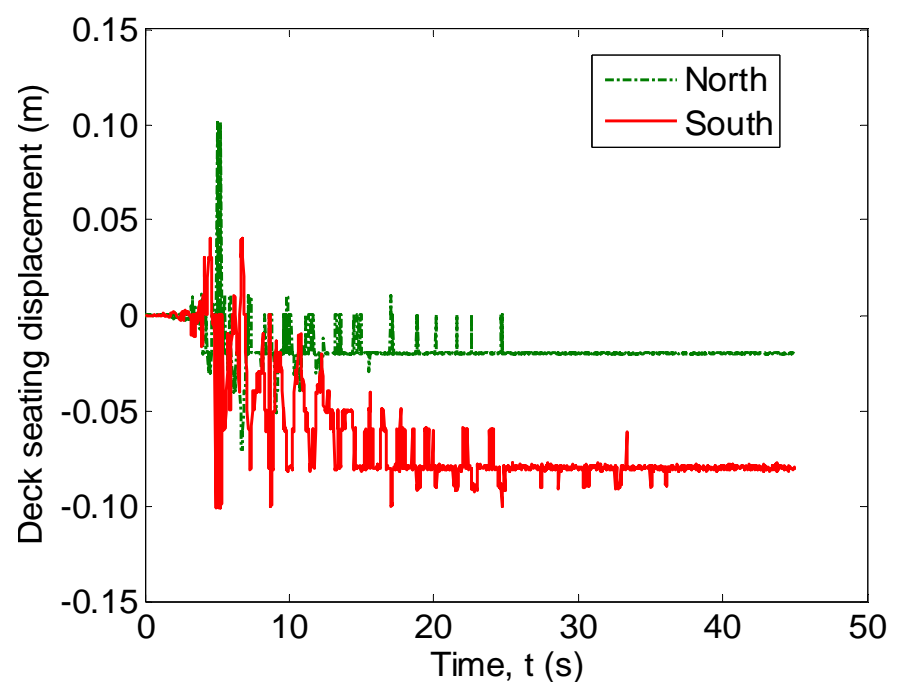

Figure 9: Deck seating displacement at the north and south abutments. 

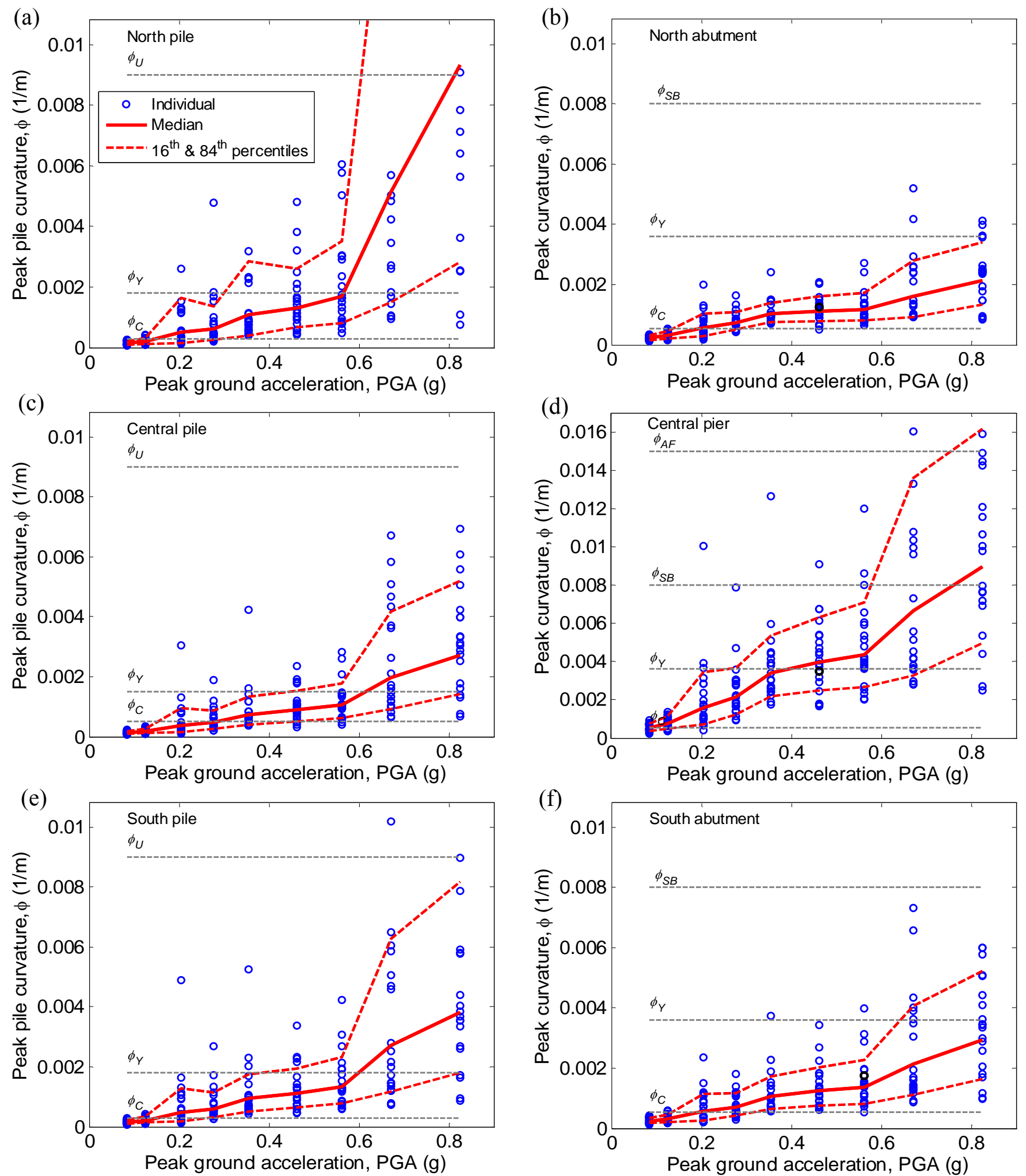

Figure 10: Probabilistic seismic response analysis results for the pile foundations, and abutments/pier at the north, central and south locations.

Median values of various damage states annotated are given in Table 4. 
(a)

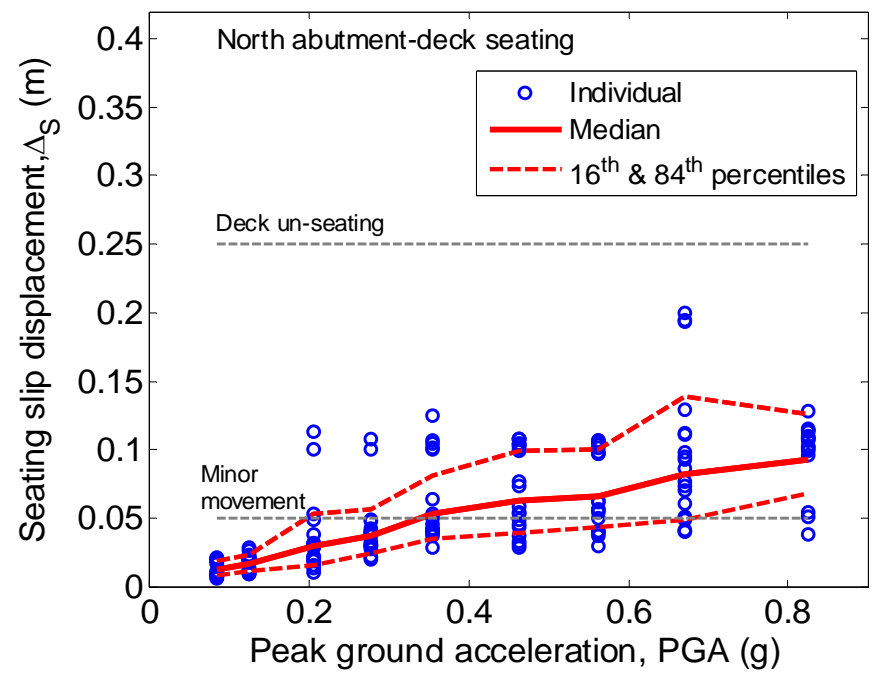

(b)

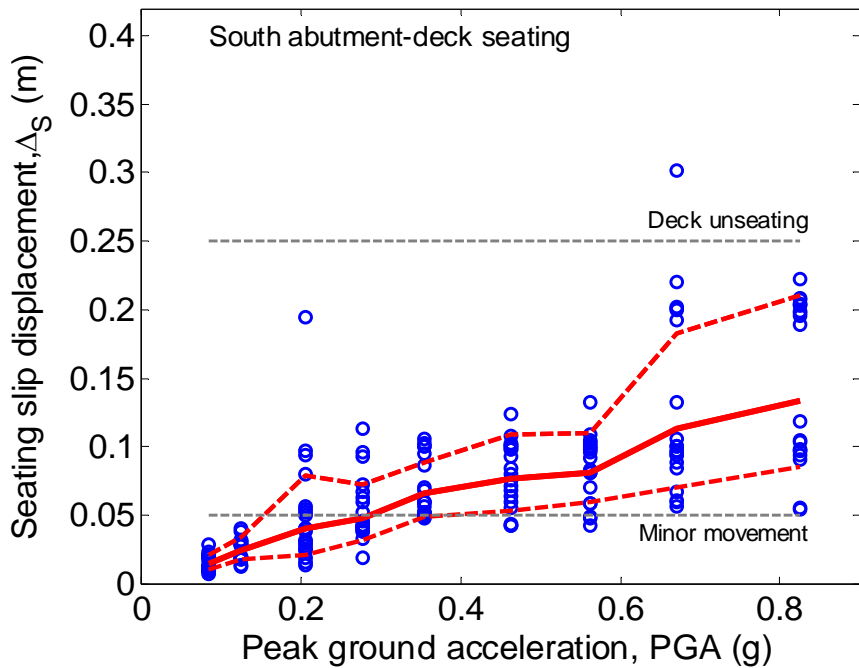

Figure 11: Probabilistic seismic response analysis results for the relative displacement between abutments and bridge deck. Median values of various damage states annotated are given in Table 4. 


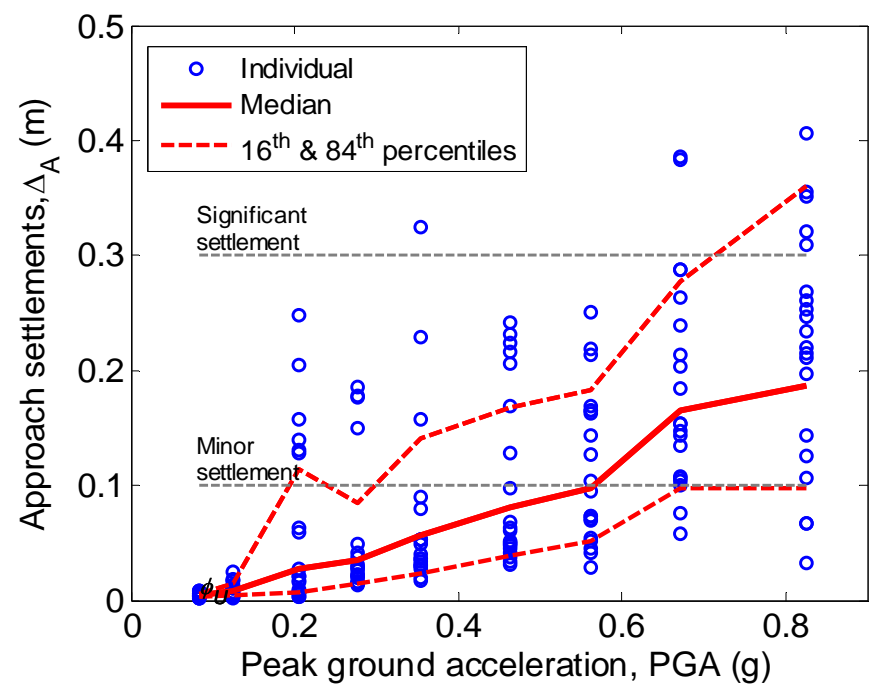

Figure 12: Probabilistic seismic response analysis results for the maximum vertical settlement at the bridge approaches. Median values of various damage states annotated are given in Table 4. 
(a)

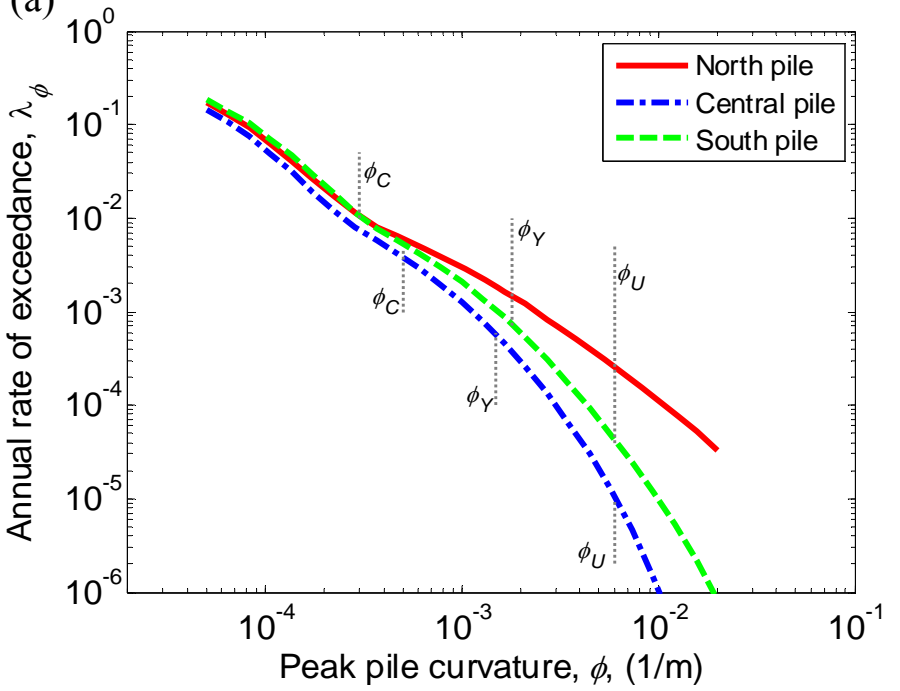

(b)

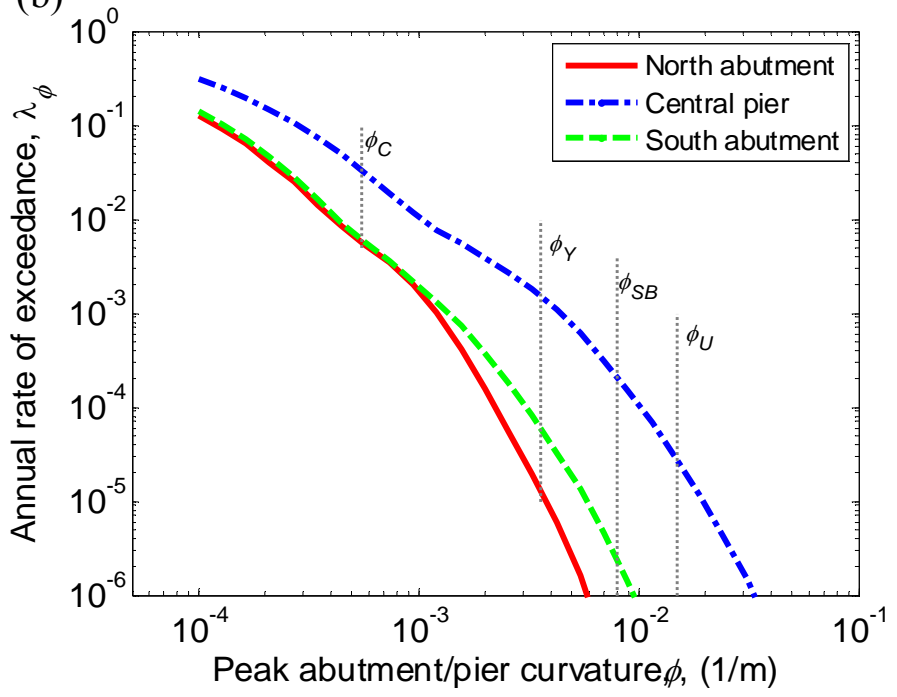

Figure 13: demand hazard curves for: (a) peak pile curvature; and (b) peak abutment/pier curvature. Median values of various damage states annotated are given in Table 4. 
(a)

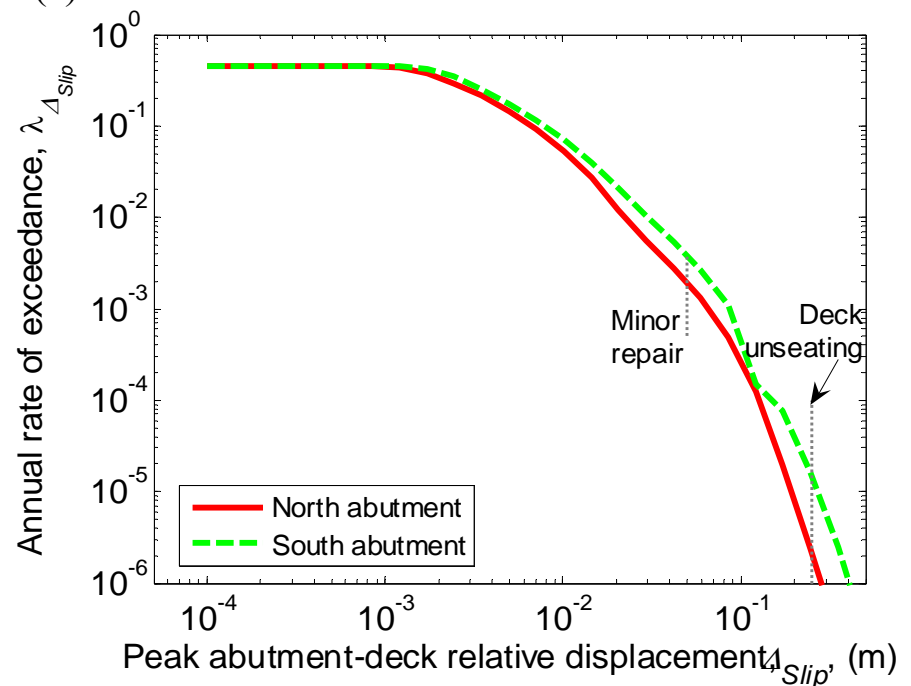

(b)

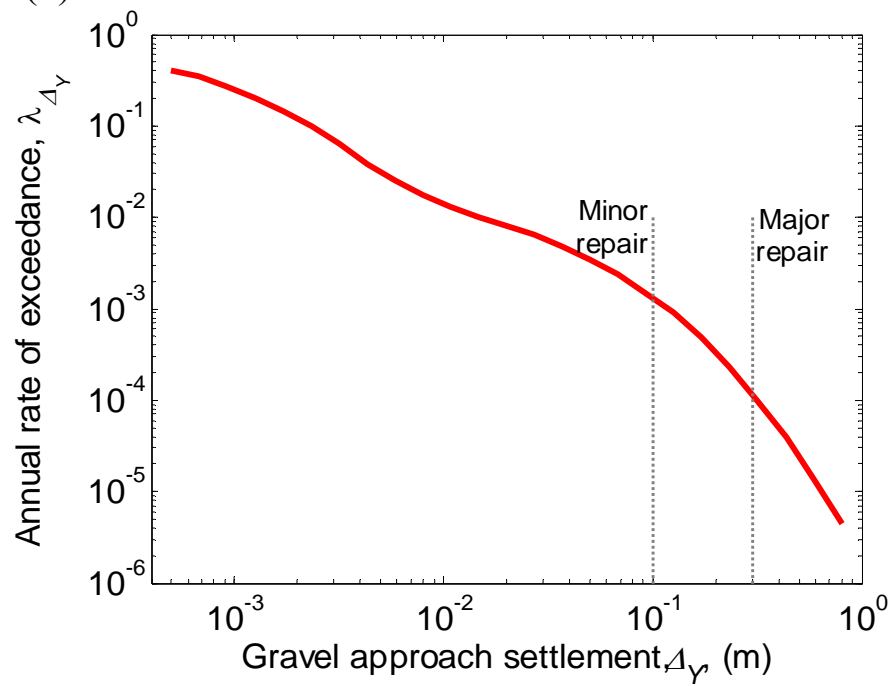

Figure 14: demand hazard curves for: (a) peak seating displacement; and (b) peak approach settlement. Median values of various damage states annotated are given in Table 4. 
(a)

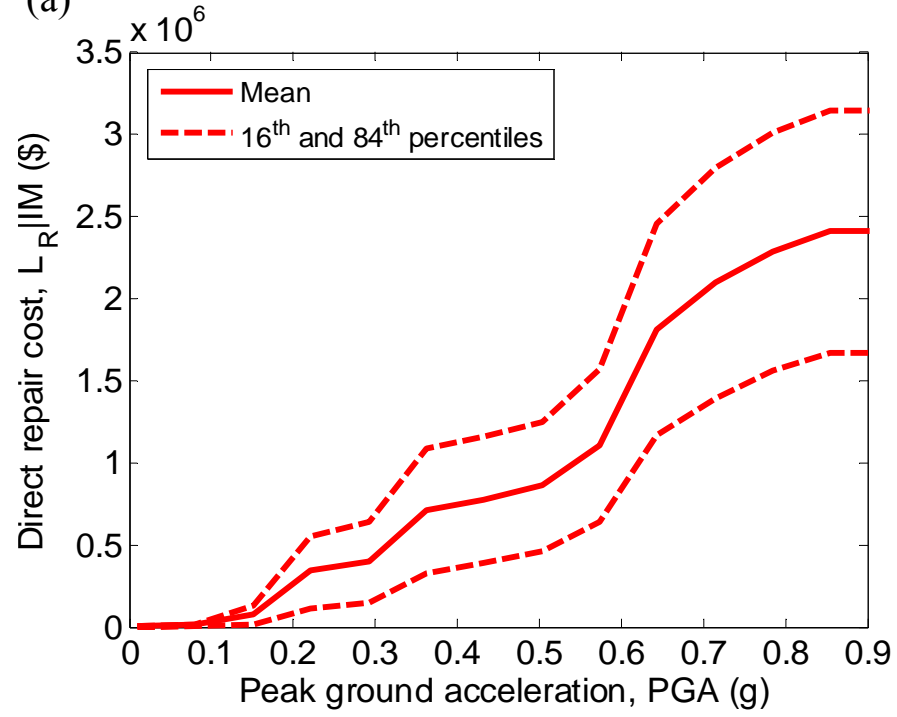

(b)

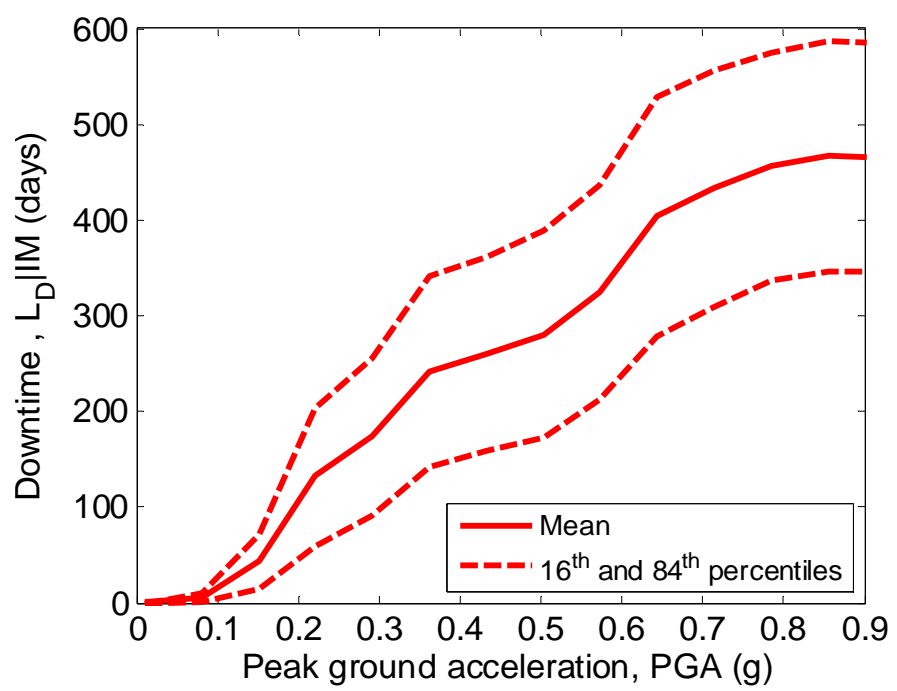

Figure 15: Distribution of: (a) direct repair cost; and (b) downtime, as a function of peak ground acceleration. 
(a)

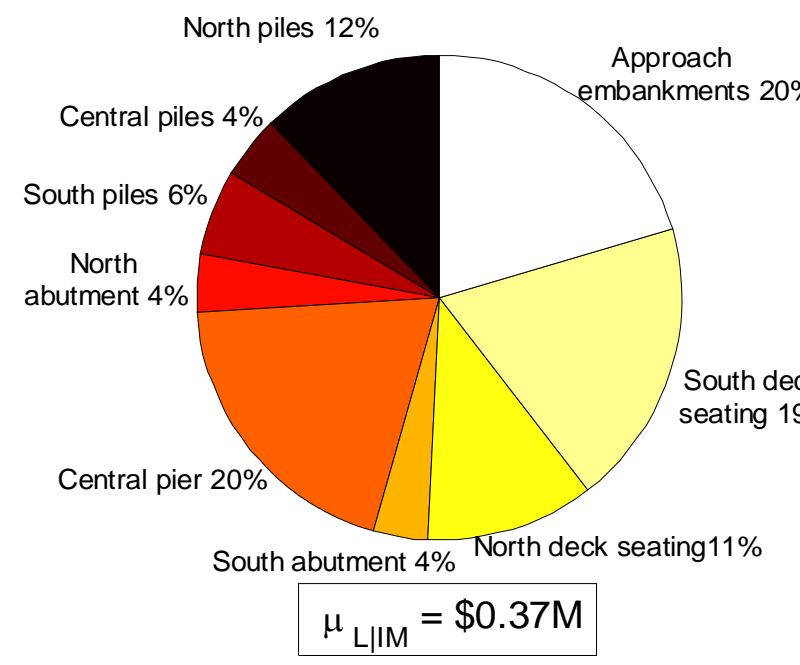

(b)

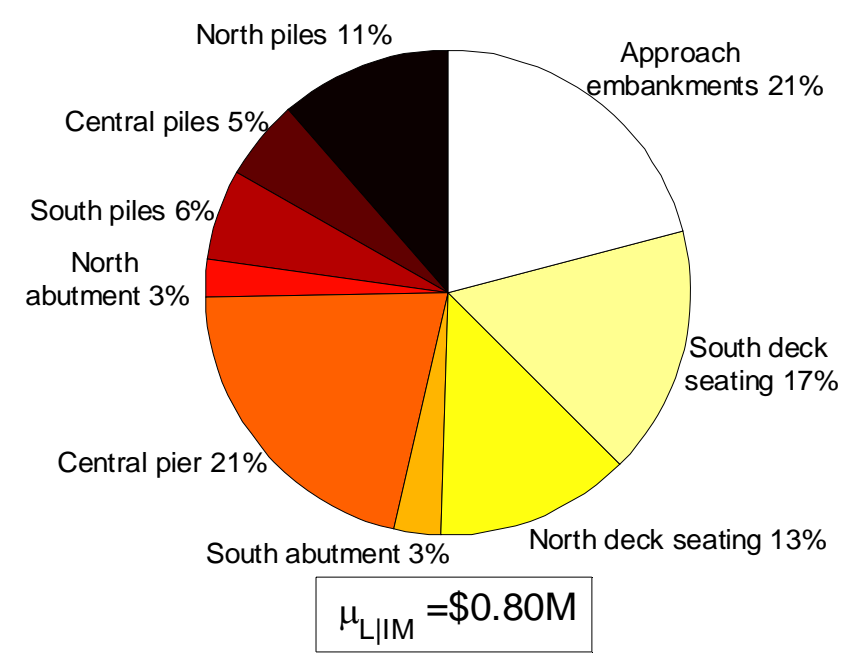

Figure 16: Deaggregation of the expected direct repair cost due to the different components of the bridge-foundation-soil system for (a) PGA $=0.27 \mathrm{~g}(10 \%$ in 50 years) and (b) PGA $=0.46 \mathrm{~g}$ ( $2 \%$ in 50 years). 
(a)

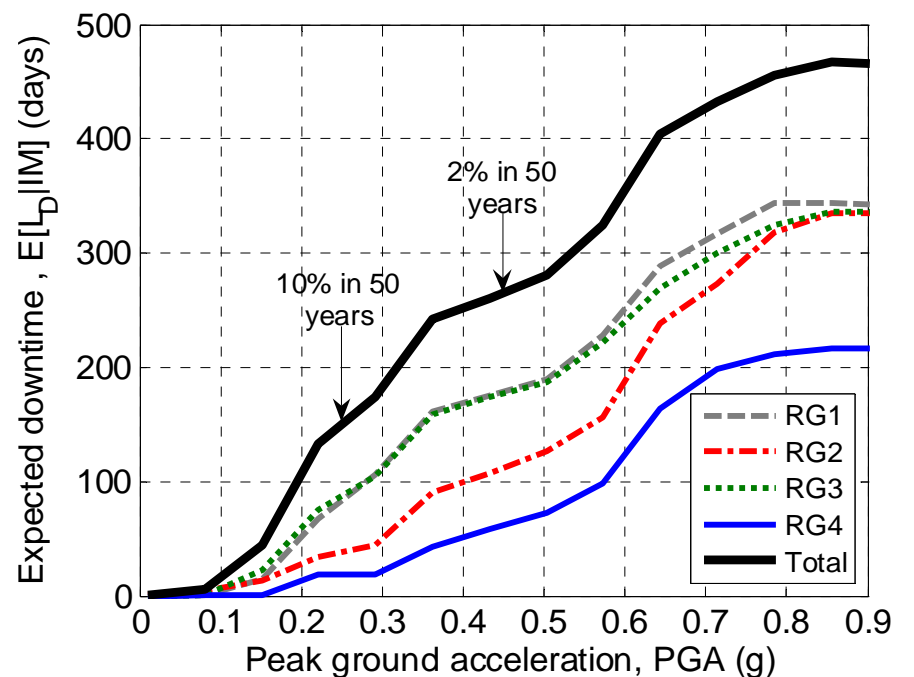

(b)

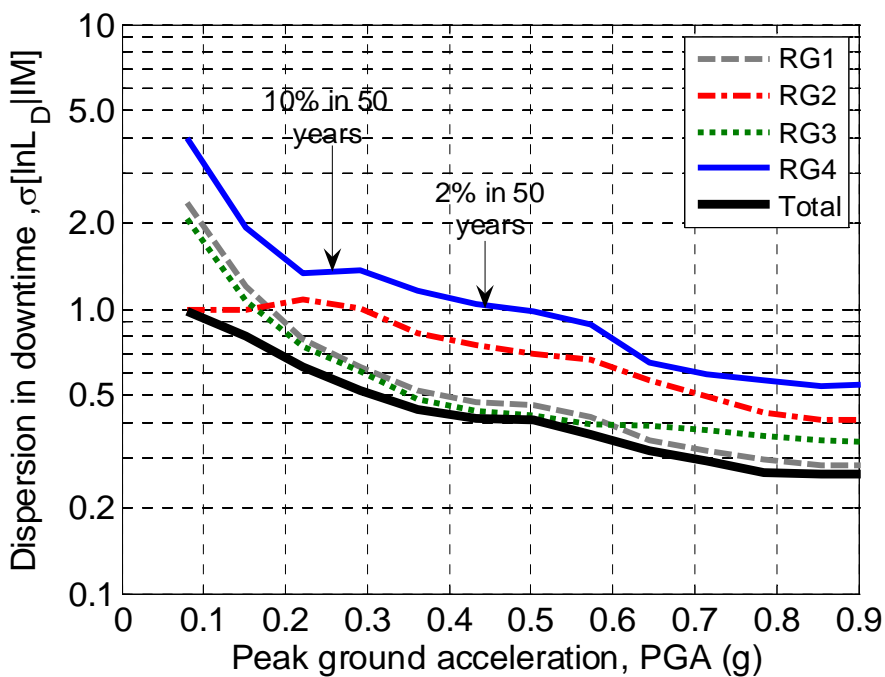

Figure 17: (a) expected value; and (b) dispersion, in the downtime for the various repair groups of the bridge-foundation-soil system as a function of ground motion intensity. 
(a)

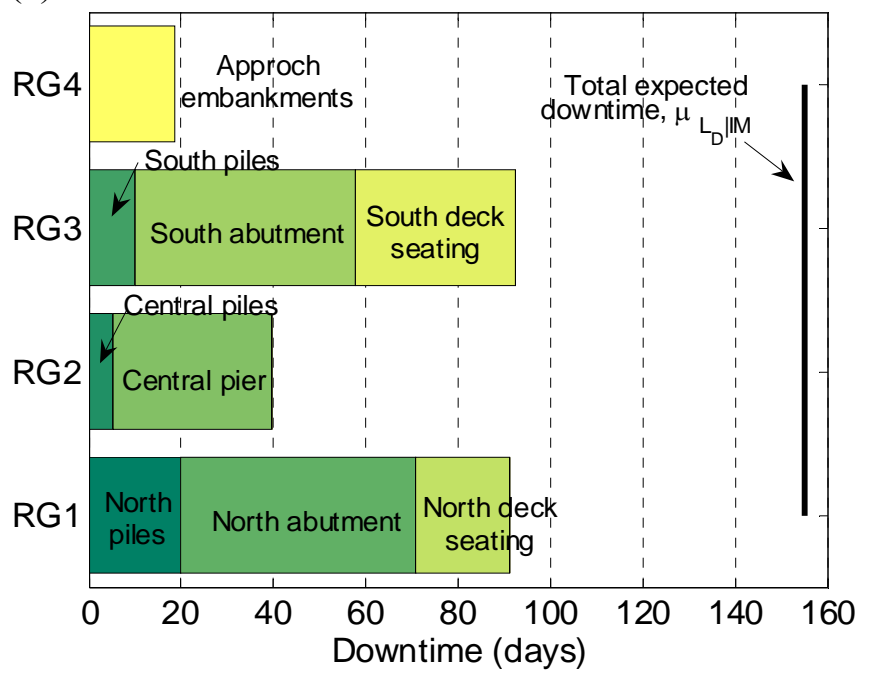

(b)

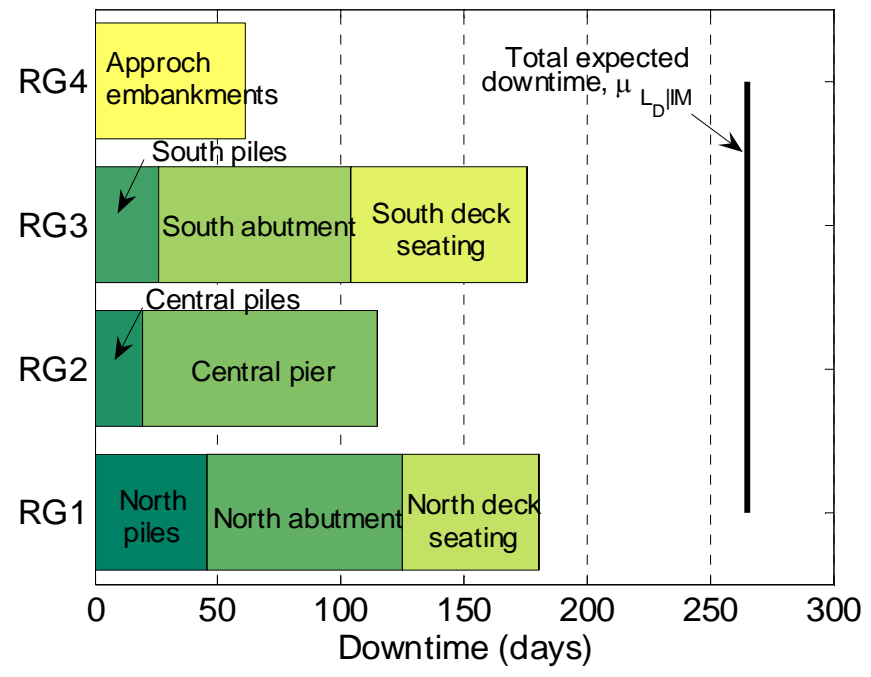

Figure 18: Deaggregation of the expected downtime due to the different components of the bridge-foundation-soil system for (a) $\mathrm{PGA}=0.27 \mathrm{~g}(10 \%$ in 50 years) and (b) PGA $=0.46 \mathrm{~g}$ ( $2 \%$ in 50 years). 


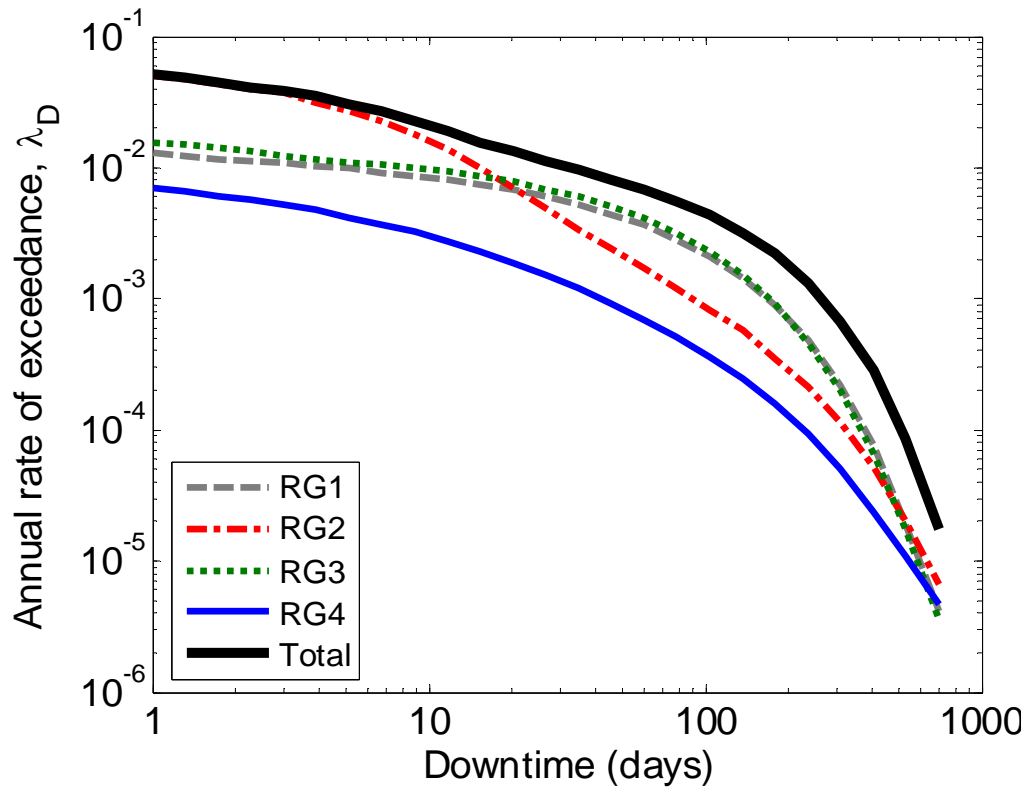

Figure 19: Downtime risk curve for the four repair groups and the entire bridge-foundation-soil system. 


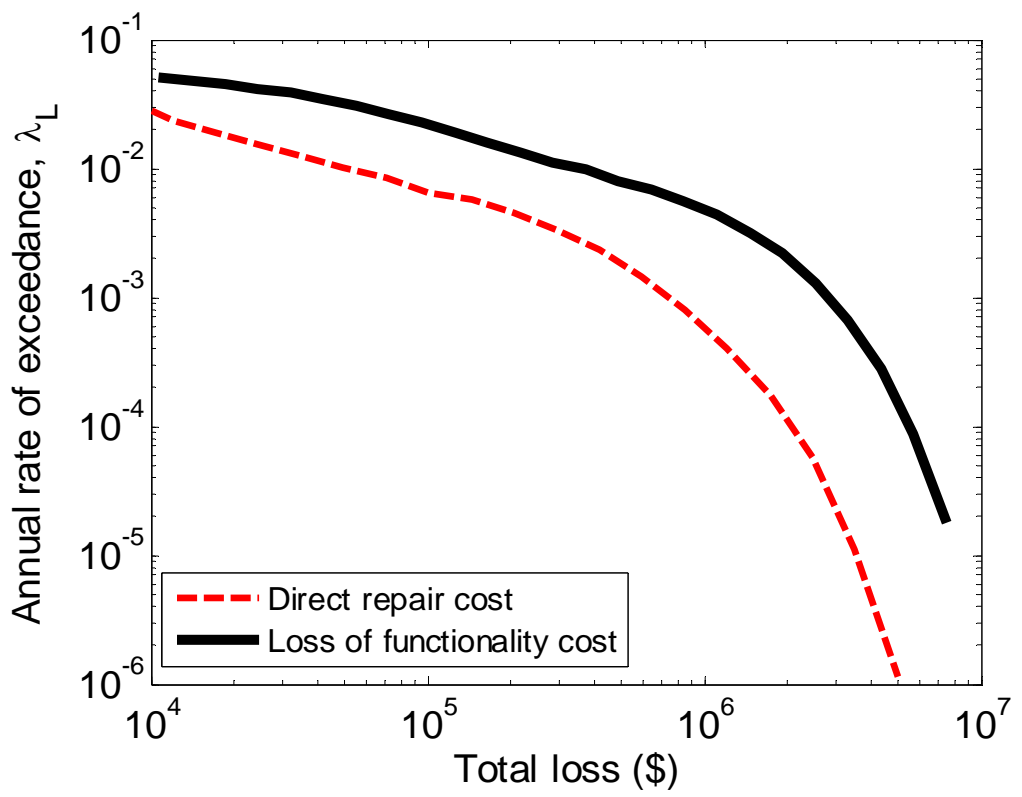

Figure 20: Comparison of the annual rate of exceedance of losses due to direct repair cost and loss of functionality. 